\title{
RESEARCH
}

Open Access

\section{The blood-brain barrier is disrupted in Machado-Joseph disease/spinocerebellar ataxia type 3: evidence from transgenic mice and human post-mortem samples}

Diana Duarte Lobo ${ }^{1 \dagger}$, Rui Jorge Nobre ${ }^{1,2,3,4+}$, Catarina Oliveira Miranda ${ }^{1,2,3 \dagger}$, Dina Pereira ${ }^{1,2}$, João Castelhano ${ }^{5}$, José Sereno ${ }^{5,6}$, Arnulf Koeppen ${ }^{7,8}$, Miguel Castelo-Branco ${ }^{5,6}$ and Luís Pereira de Almeida ${ }^{1,2,4,9^{*}}$ (D)

\begin{abstract}
Blood-brain barrier (BBB) disruption is a common feature in neurodegenerative diseases. However, BBB integrity has not been assessed in spinocerebellar ataxias (SCAs) such as Machado-Joseph disease/SCA type 3 (MJD/SCA3), a genetic disorder, triggered by polyglutamine-expanded ataxin-3. To investigate that, BBB integrity was evaluated in a transgenic mouse model of MJD and in human post-mortem brain tissues.

Firstly, we investigated the BBB permeability in MJD mice by: i) assessing the extravasation of the Evans blue (EB) dye and blood-borne proteins (e.g fibrinogen) in the cerebellum by immunofluorescence, and ii) in vivo Dynamic Contrast Enhanced-Magnetic Resonance Imaging (DCE-MRI). The presence of ataxin-3 aggregates in brain blood vessels and the levels of tight junction (TJ)-associated proteins were also explored by immunofluorescence and western blotting. Human brain samples were used to confirm BBB permeability by evaluating fibrinogen extravasation, co-localization of ataxin-3 aggregates with brain blood vessels and neuroinflammation. In the cerebellum of the mouse model of MJD, there was a 5-fold increase in EB accumulation when compared to age-matched controls. Moreover, vascular permeability displayed a 13-fold increase demonstrated by DCE-MRI. These results were validated by the 2 -fold increase in fibrinogen extravasation in transgenic animals comparing to controls. Interestingly, mutant ataxin-3 aggregates were detected in cerebellar blood vessels of transgenic mice, accompanied by alterations of TJ-associated proteins in cerebellar endothelial cells, namely a 29\% decrease in claudin-5 oligomers and a 10-fold increase in an occludin cleavage fragment. These results were validated in postmortem brain samples from MJD patients as we detected fibrinogen extravasation across BBB, the presence of ataxin-3 aggregates in blood vessels and associated microgliosis.

(Continued on next page)
\end{abstract}

\footnotetext{
* Correspondence: luispa@cnc.uc.pt

${ }^{+}$Diana Lobo, Rui Jorge Nobre and Catarina Oliveira Miranda contributed equally to this work.

${ }^{1}$ CNC - Center for Neuroscience and Cell Biology of Coimbra, Molecular

Therapy of Brain Disorders Group, University of Coimbra, Rua Larga, 3004-504 Coimbra, Portugal

${ }^{2}$ CIBB- Center for Innovative Biomedicine and Biotechnology; Vectors, Gene and Cell Therapy Group, University of Coimbra, 3004-504 Coimbra, Portugal Full list of author information is available at the end of the article
}

(c) The Author(s). 2020 Open Access This article is licensed under a Creative Commons Attribution 4.0 International License, which permits use, sharing, adaptation, distribution and reproduction in any medium or format, as long as you give appropriate credit to the original author(s) and the source, provide a link to the Creative Commons licence, and indicate if changes were made. The images or other third party material in this article are included in the article's Creative Commons licence, unless indicated otherwise in a credit line to the material. If material is not included in the article's Creative Commons licence and your intended use is not permitted by statutory regulation or exceeds the permitted use, you will need to obtain permission directly from the copyright holder. To view a copy of this licence, visit http://creativecommons.org/licenses/by/4.0/ The Creative Commons Public Domain Dedication waiver (http://creativecommons.org/publicdomain/zero/1.0/) applies to the data made available in this article, unless otherwise stated in a credit line to the data. 


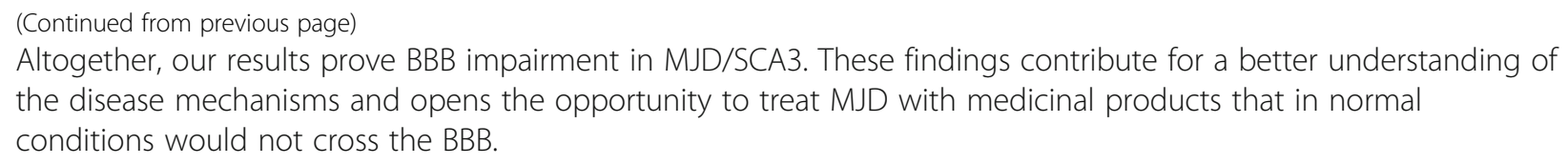

Keywords: Machado-Joseph disease (MJD), Spinocerebellar Ataxia type 3 (SCA3), Blood-brain barrier (BBB), Tight junctions (TJ), Dynamic contrast enhanced-magnetic resonance imaging (DCE-MRI)

\section{Introduction}

Machado-Joseph disease (MJD), or spinocerebellar ataxia type 3 (SCA3), is a neurodegenerative disorder caused by an expansion in the number of CAG repeats in the $A T X N 3 / M J D 1$ gene resulting in an expanded polyglutamine tract in the ataxin-3 protein [51, 63]. Although ataxin-3 functions are still poorly understood, this protein is known as a deubiquitinating enzyme involved in protein quality-control, particularly within the proteasome system, regulating the ubiquitinated status of many proteins; moreover, ataxin-3 is involved in transcription regulation, cytoskeleton organization and myogenesis $[12,16,55,64]$.

In the context of MJD, the expanded polyglutamine tract in ataxin-3 promotes its aggregation and toxic gain of function $[15,19]$. Indeed, expanded ataxin-3 hampers several cellular mechanisms, such as transcription regulation, mitochondrial activity and autophagy, and induces neuroinflammation $[6,28,42,50]$. Ultimately, this results in neuropathology and neurodegeneration in numerous brain regions, such as the cerebellum, particularly the deep cerebellar nuclei, the brainstem, the spinal cord and the striatum [1]. Generally, neuropathological features are translated into disease symptoms, namely progressive gait ataxia, but also dysarthria and dysphagia, oculomotor disturbances, among others [39, 61].

To this date, there is no treatment available for MJD patients, although many efforts have been done [40]. In particular, the development of systemically administered MJD therapies has been of great relevance [10, 48, 60]. For instance, a phase 2 clinical trial with umbilical cordderived mesenchymal stem cell therapy for SCA patients is now open (NCT03378414) that includes both intrathecal and intravenous infusions of cells. Moreover, there is great prospect for gene silencing approaches, ideally administered through minimally-invasive routes. In that context, it remains extremely relevant to understand the level of permeability of the blood-brain barrier (BBB) in MJD. Despite the fact that BBB integrity has been proven to be affected in other neurodegenerative disorders, it remains an open question for MJD, and spinocerebellar ataxias in general.

BBB is comprised in the concept of the neurovascular unit and establishes an interface between blood and the brain parenchyma. The main BBB components are the endothelial cells of brain blood vessels, which are supported by pericytes, both encircled by the basement membrane, and astrocytic end-feet. Distinctive features of $\mathrm{BBB}$, like low paracellular diffusion in the brain endothelium, are maintained because of the absence of fenestrations due to the existence of junctional complexes, namely tight junctions (TJs) and adherens junctions (reviewed in [34]). The disarrangement of these structures usually leads to an increased permeability of brain blood vessels and, consequently, there is an increased vulnerability of brain parenchyma to toxic blood-born substances, viruses, systemic inflammation and other threats to neuronal homeostasis. Alzheimer's, Parkinson's, Multiple Sclerosis, Huntington's and Amyotrophic Lateral Sclerosis, among other neurological diseases have been shown to bear BBB disruption (reviewed by Zlokovic and colleagues) [75]. This is frequently associated with loss of TJs integrity, due to alterations in the expression of the associated proteins, lack of its proper function, their distribution or their degradation [75].

Based on the evidence presented above, in the present study, the main objective was to evaluate $\mathrm{BBB}$ integrity in MJD. For this purpose, we assessed BBB permeability in the cerebellum of a transgenic mouse model of MJD through ex vivo assays, i.e. monitoring Evans blue (EB) brain accumulation and fibrinogen extravasation, and by using a powerful non-invasive in vivo technology named Dynamic Contrast Enhanced-Magnetic Resonance Imaging (DCE-MRI). We then investigated the mechanisms involved in $\mathrm{BBB}$ disruption, by analyzing the presence of mutant ataxin-3 aggregates in cerebellar blood vessels and the levels of TJ-associated proteins by Western blot. Finally, post-mortem human brain samples from MJD patients and controls were examined for fibrinogen extravasation across BBB, for the presence of ataxin- 3 aggregates in brain blood vessels and neuroinflamation.

Our results indicate that BBB is disrupted in MJD, which brings a novel perspective for the disease mechanism itself and provides an opportunity for therapeutic designs as well as strategies of administration.

\section{Materials and methods}

\section{Animals}

The investigated transgenic animal model expresses a truncated form of human ataxin-3 with 69 CAG repeats, 
preceded by the hemagglutinin (HA) epitope in C57BL/6 background [65]. The transgene expression is driven by the L7 promoter, specific for Purkinje cells. A colony of this transgenic mouse model was established at the Center for Neuroscience and Cell Biology of the University of Coimbra. The colony was maintained by backcrossing C57BL/6 females with heterozygous males. Transgenic mice and age-matched wild-type animals were housed in a temperature-controlled room on a $12 \mathrm{~h}$ light $/ 12 \mathrm{~h}$ dark cycle with food and water provided ad libitum. Genotyping was performed by Polymerase Chain Reaction.

All animal experiments were carried out in accordance with the European Community Council Directive (2010/ $63 / \mathrm{EU}$ ) for the care and use of laboratory animals and previously approved by the Responsible Organization for the Animals Welfare of the Faculty of Medicine and Center for Neuroscience and Cell Biology of the University of Coimbra (ORBEA and FMUC/CNC, Coimbra, Portugal).

\section{Human post-mortem tissue}

Postmortem tissues from the striatum of three patients (Supplementary Table 1), who were genetically diagnosed with MJD (Mean age: $61 \pm 6$ years, Number of CAGs in mutant allele: $62 \pm 7$ CAGs) and two controls (65 and 56 years-old) with no evidence of neurologic diseases were obtained from the Neurology and Pathology Services, VA Medical Center, Albany Medical College, Albany, New York, NY, USA. After dissection, tissue was fixed in cold $10 \%$ neutral buffered formalin and cut into $35 \mu \mathrm{m}$ sections in a cryostat (Leica CM3050S).

\section{Experimental design}

The present study included a total of 26 animals, 11 MJD transgenic mice and 15 wild-type littermates.

Firstly, 11-month-old MJD transgenic mice $(n=4,2$ males and 2 females) and age-matched wild-type animals ( $n=6,3$ males and 3 females) were injected with Evans Blue (EB) in the caudal vein to evaluate BBB permeability in adult mice.

In a second experiment, to confirm $\mathrm{BBB}$ permeability and assess brain vasculature non-invasively we performed DCE-MRI in 16-17.5-month old MJD transgenic ( $n=6,5$ females and 1 male) and age-matched wild-type mice ( $n=7,3$ females and 4 males).

Fibrinogen extravasation across BBB, density of blood vessels, presence of ataxin- 3 aggregates within the cerebellar blood vessels, and the levels of TJ-associated proteins in the cerebellum were investigated at an extended group of 16-17.5-month-old mice, in a total of 7 transgenic mice ( 2 males and 5 females) and 9 (4 males and 3 females) age-matched control animals.

Finally, striata from human post-mortem tissue of 3 MJD patients and 2 controls were used to investigate
BBB permeability by quantifying fibrinogen extravasation across brain blood vessels and also to check for the presence of ataxin-3 aggregates in blood vessels, both assessments by immunofluorescence.

\section{EB injection, tissue collection and quantification}

Mice were injected with $2 \%$ EB $(100 \mu \mathrm{L} / 30 \mathrm{~g})$ in the caudal vein. After $30 \mathrm{~min}$, animals were sacrificed by transcardial perfusion followed by brain and liver dissection. Left hemisphere was used for fluorescence microscopy analysis and right hemisphere used for spectrophotometric analysis. In the last, cerebellum and cerebrum were analyzed separately.

\section{EB quantification by spectrophotometry}

The liver and the right hemisphere of the brain (cerebellum and cerebrum in separate) were incubated overnight with pure formamide ( 6 times the volume of its weight) at $70{ }^{\circ} \mathrm{C}$. Subsequently, the organs were centrifuged at maximum speed, at $4{ }^{\circ} \mathrm{C}$, and the supernatant absorbance was measured at $620 \mathrm{~nm}$ and $720 \mathrm{~nm}$ using the light detector Fluorimeter SpectraMax Gemini EM (Molecular Devices). Absorbance values at $620 \mathrm{~nm}$ were subtracted to absorbance values at $720 \mathrm{~nm}$ and compared with a pre-defined standard curve. Finally, EB concentration in the cerebrum and cerebellum was also normalized with liver concentration, in order to exclude slight discrepancies in the amount of EB reaching peripheral organs due to the injection per se.

\section{EB detection by fluorescence microscopy}

Left brain hemispheres were sliced into $35 \mu \mathrm{m}$ sagittal sections and placed directly onto superfrost microscope slides (Thermo Scientific). Nuclear staining was performed with DAPI (4',6-diamidino-2-phenylindole). Images were acquired with Zeiss Axio Imager Z2 microscope (Carl Zeiss Microimaging), equipped with a High Resolution Monochromatic Camera and with PlanApochromat 20X/0.8 M27 objective.

\section{Dynamic contrast-enhanced-magnetic resonance imaging (DCE-MRI)}

Acquisition of in vivo images of mice $(n=6 \mathrm{MJD} ; n=7$ wild-type) were conducted with a $9.4 \mathrm{~T}$ magnetic resonance small animal scanner BioSpec 94/20, with a standard Bruker cross coil setup using a volume coil for excitation (with $86 / 112 \mathrm{~mm}$ of inner/outer diameter, respectively) and quadrature mouse surface coil for signal detection (Bruker Biospin, Ettlingen). Animals were anesthetized with isoflurane (1-2\%) (delivered through the system E-Z SA800, Euthanex, Palmer), with constant temperature monitoring (Haake SC 100, Thermo Scientific) and assessment of cardiorespiratory function (1030, SA Instruments Inc., NY). 
Dynamic contrast-enhanced images were acquired with a fat-saturated T1-weighted gradient-echo sequence with parameters: $\mathrm{TR} / \mathrm{TE}=251.446 / 2.5 \mathrm{~ms}, \quad \mathrm{FA}=70^{\circ}$, FOV $=20 \times 20 \mathrm{~mm} 2$, matrix size $=108 \times 71,24$ slices (coronal orientation), slice thickness $=0.5 \mathrm{~mm}, 40 \mathrm{dy}-$ namics acquired, 7 averages, scan time per dynamic $=$ $125 \mathrm{~s}$, total scan time $=1 \mathrm{~h}$ and $23 \mathrm{~min}$. The gadoliniumbased contrast agent named Gadobutrol (Gadovist, LUSAL) was administered intraperitoneally, after the acquisition of 8 baseline and 32 dynamic scans which were acquired following the injection.

DCE data were analyzed offline using homemade software implemented in Matlab (v2013a, Mathworks, Natick) to obtain tissue/contrast enhancement curves. DCE data were pre-processed (e.g. rescaled) and filtering (e.g. excluding voxels outside the brain) and movement corrections were applied as previously described [5, 49]. A Region of interest (ROI) was drawn for each animal corresponding to the cerebellum in separate using a semiautomatic procedure. The mean variation of signal intensity, or cerebellum enhancement curve, as a function of time was then quantified in the predefined ROI. Mean area under the curve (AUC) was calculated to evaluate perfusion and vascular permeability.

\section{Blood-brain barrier analysis by immunofluorescence and western blot}

Wild-type and MJD transgenic mice with 16-17.5 months old were anaesthetized via intraperitoneal route and transcardially perfused with cold PBS, pH 7.4. Perfused cerebella were then dissected. The left hemisphere of the cerebellum was cut into $35 \mu \mathrm{m}$ sagittal sections in a cryostat (Leica CM3050S) and placed directly onto superfrost microscope slides (Thermo scientific) to be used in immunofluorescence analysis. The right half of the cerebellum was used for protein extraction and further western blot analysis.

\section{Immunofluorescence}

Cerebellum sections were hydrated and blocked/permeabilized with $3 \%$ bovine serum albumin (BSA) and 0.1\% Triton X-100. Then, sections were incubated for $48 \mathrm{~h}$ at $4{ }^{\circ} \mathrm{C}$ with the respective primary antibodies diluted in 0.3\% BSA: goat anti-Collagen type IV (CoIV; 1:250, Millipore Cat\# AB769, RRID:AB_92262), rabbit antiFibrin/FITC (1:40, Dako Cat\# F011102-2) and mouse anti-HA (1:500, BioLegend Cat\# MMS-101P-1000, RRID:AB_291259). Co-immunofluorescence was performed for the following combinations: fibrinogen with CoIV and ataxin-3 aggregates (HA) with CoIV. Afterwards, sections were incubated with the corresponding secondary antibodies: anti-goat Alexa Fluor 568 (1:200, Thermo Fisher Scientific Cat\# A-11057, RRID:AB 2534104) or anti-mouse Alexa Fluor 488 (1:200, Thermo
Fisher Scientific Cat\# A-11055, RRID:AB_2534102) or anti-rabbit Alexa Fluor 647, during $2 \mathrm{~h}$ at room temperature before nuclear staining with DAPI. Finally, slides were coverslipped on Dako fluorescence mounting medium (S3023, Dako).

\section{Quantitative analysis of extravascular fibrinogen}

Extravascular fibrinogen in the mice cerebella was quantified by measuring the percentage of surface area positive for fibrinogen staining outside blood vessels, as previously described by Drouin-Ouellet et al. [13]. Briefly, images of one section per animal corresponding to a similar cerebellar region per animal stained with primary antibodies against CoIV and fibrin were acquired with Plan-Apochromat 20X/0.8 M27 objective in Zeiss Axio Imager Z2 microscope. Subsequently, a magenta mask for CoIV and a yellow mask for fibrinogen staining were obtained with Image J $1.51 \mathrm{~h}$. The masks were then merged in Adobe Photoshop 2017 (Adobe Systems Incorporated) showing the co-localization of CoIV and fibrinogen, which appeared in white (resulting from the merge of magenta and yellow). After removing magenta and white from the image, leaving only extravascular fibrinogen staining in yellow, the percentage of surface area was measured using Image J $1.51 \mathrm{~h}$. Percentage of CoIV surface area was measured using also Image J $1.51 \mathrm{~h}$. Cerebellum sections of $4 \mathrm{MJD}$ and 4 wild-type mice with 16-17.5 months old were analyzed.

\section{Co-localization of ataxin-3 aggregates with ColV-positive blood vessels}

Images of cerebellar sections stained with anti-HA and anti-CoIV were acquired with a confocal Carl Zeiss LSM 710 (Carl Zeiss Microimaging), equipped with a QUASAR detection unit and the Plan-Apochromat 63X/1.4 DIC,M27 oil objective. One cryosection per animal corresponding to the same cerebellar region was used to analyze immunofluorescence images. Evaluation of the presence of ataxin-3 aggregates (HA staining) within CoIV-positive blood vessels was performed in serial Zstacks using Zen 2.3 software (Zeiss) in 6 MJD transgenic mice with 16-17.5 months old.

\section{Protein extraction and western blotting}

The right side of the cerebellum was initially homogenized with Ambion TRIzol reagent (Fisher Scientific) and then subjected to density gradient with chloroform to remove the RNA aqueous phase. DNA was precipitated with $100 \%$ ethanol, leaving the protein in the phenol-ethanol phase. Isopropanol was added to precipitate protein, which was pelleted and washed with guanidine-ethanol solution and 100\% ethanol. Dried pellet was then solubilized in urea/Dithiothreitol solution 
with protease inhibitors (Roche Diagnostics), followed by incubation at $95^{\circ} \mathrm{C}$ during $5 \mathrm{~min}$.

Bradford protein assay (BioRad) was used to determine protein concentration. Thirty and forty micrograms of protein extract were resolved on sodium dodecyl sulfatepolyacrylamide gels. Proteins were then transferred onto a polyvinylidene difluoride membrane (Millipore), previously blocked with $5 \%$ non-fat milk powder dissolved in $0.1 \%$ Tween 20 in Tris-buffered saline for $1 \mathrm{~h}$ at room temperature. Membranes were then incubated overnight at $4{ }^{\circ} \mathrm{C}$ with primary antibodies: rabbit antiZonula occludens-1 (ZO-1, 1:1000, Thermo Fisher Scientific Cat\# 61-7300, RRID:AB_2533938), rabbit anticlaudin-5 (1:5000, Thermo Fisher Scientific Cat\# 341600, RRID:AB_2533157), rabbit anti-occludin Cterminal (1:500, Thermo Fisher Scientific Cat\# 71-1500, RRID:AB_2533977), anti-occludin N-terminal (1:1000, Millipore, Cat\# ABT146 supplementary data), rabbit anti-Cluster of differentiation 31 (CD31, 1:500, Abcam Cat\# ab28364, RRID:AB_726362). The corresponding alkaline phosphatase-linked goat anti-rabbit secondary antibody was incubated for $2 \mathrm{~h}$ at room temperature. Bands were detected after incubation with Enhanced Chemifluorescence Substrate (GE Healthcare) and visualized in chemifluorescence imaging (ChemiDocTM Touch Imaging System, Bio-Rad Laboratories). Semiquantitative analysis was carried out based on the bands of scanned membranes using Image J $1.51 \mathrm{~h}$ (National Institutes of Health) and normalized relatively to the amount of GAPDH.

\section{Immunofluorescence in human post-mortem tissue}

Anti-ataxin-3 (1H9, 1:1000, HenBiotech Cat\# HBT018100) and anti-CoIV (1:250, Millipore, Cat\# AB769, RRID:AB_92262) immunostainings were performed as previously described for animal immunofluorescence. Images were acquired with a confocal Carl Zeiss LSM 710 (Carl Zeiss Microimaging), equipped with a QUASAR detection unit and the Plan-Apochromat 63X/1.4 DIC,M27 oil objective. Similarly, images from double staining for fibrinogen (1:40, Dako, Cat\# F011102-2) and CoIV (1:250, Millipore, Cat\# AB769, RRID:AB_ 92262) were acquired with Cell Observer Spinning Disk equipped with a highly sensitive electron multiplying camera (EM-CCD Evolve Delta) and a Plan-Apochromat 20X/0.8 M27 in one cryosection of tissue per individual. Analysis was performed according to the protocol described above for mice brain sections, to quantify the percentage of surface area of extravascular fibrinogen. Percentage of CoIV surface area was also measured using Image J $1.51 \mathrm{~h}$. Regarding neuroinflammation immunostainings, the antibodies used were: rabbit antiionized calcium-binding adapter molecule 1 (Iba1, 1:500, Wako, Cat\# 019-19,741), mouse anti-Glial fibrillary acidic protein (GFAP, 1:500, Merck Millipore, Cat\# IF03L) and goat anti-CoIV. The secondary antibodies were anti-goat Alexa Fluor 568 (1:200, Thermo Fisher Scientific Cat\# A-11057, RRID:AB_2534104), anti-rabbit Alexa Fluor 488 (1:200, Thermo Fisher Scientific Cat\# A-11008) and anti-mouse Alexa Fluor 647 (1:500, Chromotek, Cat\# sms1AF647). Quantification of fluorescence intensity of GFAP and Iba1 were performed using Zen 2.3 software (Zeiss) for the same area of tissue in striatum slices from MJD patients and healthy individuals.

\section{Statistical analysis}

GraphPad Prism software was used to present data and outliers were removed according to Grubb's test (alpha = 0.05). Unpaired Student's t test, with application of Welch's correction in the case of unequal variances, was performed to compare wild-type and MJD transgenic groups. Significance was determined according to the following criteria: $P>0.05=$ not significant; ${ }^{*} P \leq 0.05$, ** $P<0.01$ *** $P<0.001$ and ***** $P<0.0001$.

\section{Results \\ Evans blue extravasation in the cerebellum of MJD transgenic mice}

EB dye has been widely used to evaluate BBB permeability, since it strongly binds albumin, a protein of around $67 \mathrm{KDa}$, which is able to cross the brain blood vessels when BBB is compromised [56]. In our first experiment, 11-month-old wild-type and MJD transgenic mice were injected with EB (2\%) in the caudal vein and sacrificed 30 min later. Next, the left hemisphere of the brain was used for fluorescence microscopy analysis, while the right hemisphere was separated into cerebrum and cerebellum and used for EB quantification by spectrophotometry (summarized in Fig. 1a).

As shown in Fig. 1b, no significant differences were observed in the levels of EB in the cerebrum of transgenic mice as compared to wild-type littermates. On the contrary, an approximately 5-fold significant increase of EB concentration was observed in the cerebellum of transgenic mice $(15.27 \pm 5.34 \mathrm{pg} / \mu \mathrm{L}$ in wild-type, $n=6$ and $77.25 \pm 14.11 \mathrm{pg} / \mu \mathrm{L}$ in MJD, $n=4$; unpaired t test, $P=0.016$ ) (Fig. 1c). Similar results were obtained when normalizing to EB levels in the liver; in the case of cerebellum, the transgenic animals showed, approximately, a 6-fold increase comparing to the ratio of EB concentrations in wild-type mice $(1.59 \pm 0.67 \mathrm{pg} / \mu \mathrm{L}$ in wild-type, $n=6 ; 9.55 \pm 1.57 \mathrm{pg} / \mu \mathrm{L}$ in MJD, $n=4$; unpaired t test, $P=0.009$ ) (supplementary Fig. 1).

Fluorescence microscopy analysis of brain tissue sections further confirmed that EB is more abundant in the cerebellum of MJD mice as compared to age-matched control subjects. In particular, EB staining revealed 


\section{a}

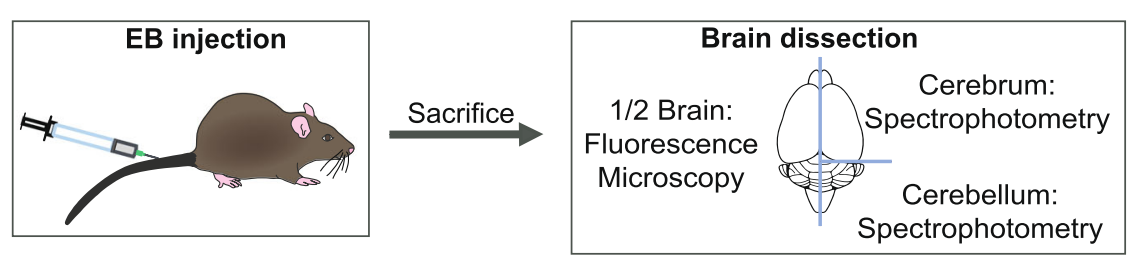

b

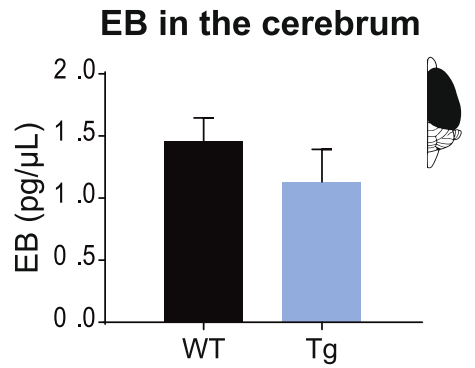

C EB in the cerebellum

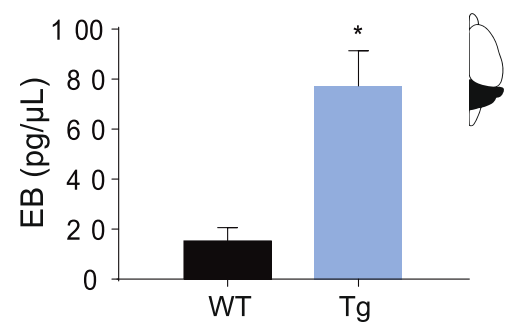

d

EB

DAPI
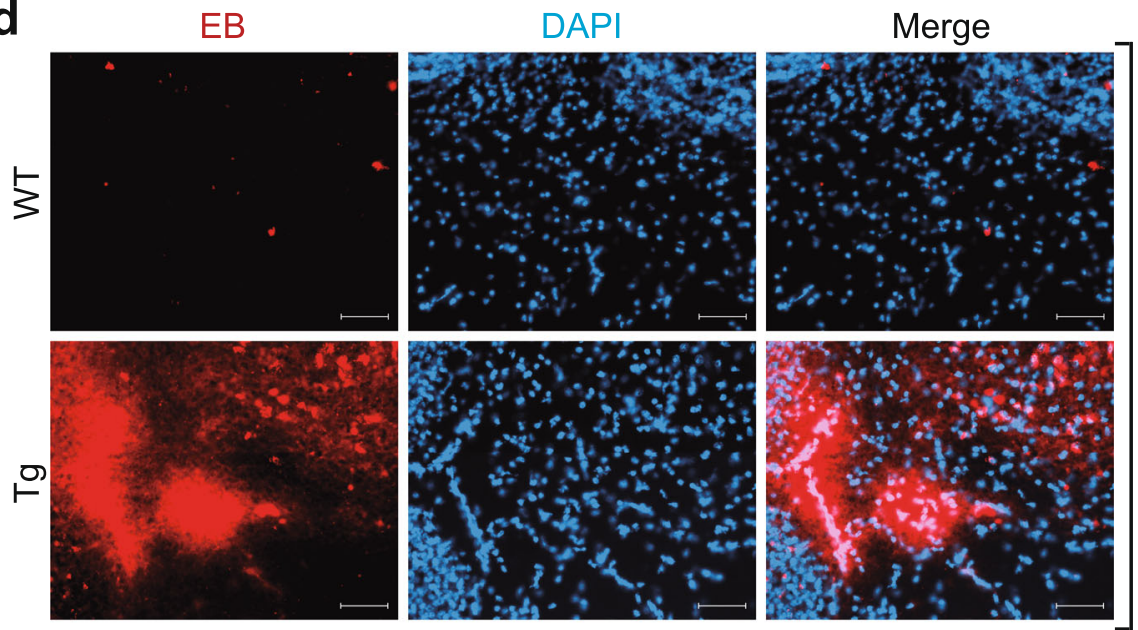

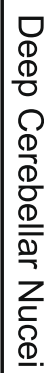

e

EB

DAPI
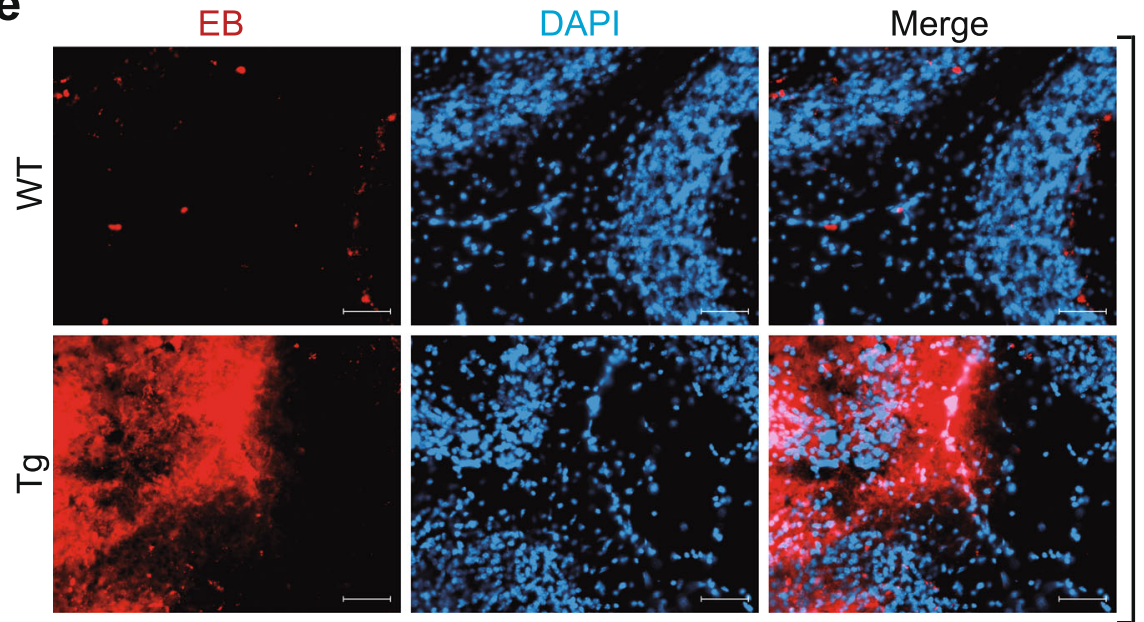

$\bar{\sigma}$
$\frac{0}{0}$
$\frac{5}{D}$
$\frac{\infty}{6}$

Fig. 1 (See legend on next page.) 
(See figure on previous page.)

Fig. 1 EB extravasation reveals BBB leakage in MJD mice. a Schematic presentation of the experimental set for EB injection $(n=4$ MJD transgenic, $\operatorname{Tg}$ and $n=6$ wild-type, WT animals; 11 month-old). $\mathbf{b}$ EB concentration $(\mathrm{pg} / \mu \mathrm{L})$ in the cerebrum showed no differences between wild-type and transgenic animals. c Cerebellum, on the other hand, exhibited a 5-fold increase of EB in MJD transgenic mice (Unpaired t test; $P=0.02$ ). $\mathbf{d}$, e Representative fluorescence images of the cerebellum of wild-type and transgenic mice revealed EB deposition mainly in deep cerebellar nuclei $(\mathrm{DCN})$ and lobule 8 and 9, respectively, of transgenic animals (Scale bars $=50 \mu \mathrm{m}$ ). Values are presented as mean \pm SEM. Unpaired t test with Welch's correction, $P>0.05=$ not significant and ${ }^{*} P \leq 0.05$

vascular leakage in the cerebellum, predominantly in deep cerebellar nuclei (DCN) (Fig. 1d) and lobules 8 and 9 (Fig. 1e).

Overall, these findings reveal an abnormal crossing of albumin from the blood to the cerebellar parenchyma, which suggest that BBB is disrupted in the cerebellum of this transgenic MJD mouse model.

\section{In vivo evidence of BBB disruption by dynamic contrast-} enhanced magnetic resonance imaging (DCE-MRI)

To further validate BBB disruption and to investigate if it might be used as a biomarker in live animals, a new set of transgenic and age-matched wild-type animals with 16-17.5 months old were analyzed by DCE-MRI two weeks before sacrifice $(n=6 \mathrm{MJD} ; n=$ 7 wild-type). The signal intensity resulting from the gadolinium-based contrast agent circulation and leakage in capillaries was recorded throughout time and analyzed by a semi-quantitative method. As illustrated in Fig. 2a, a boost in signal intensity of the contrast agent was observed in the cerebellum of MJD mice, as compared to wild-type animals. In agreement, the curve of variation of the signal intensity suggested higher blood volume in the cerebellum of transgenic mice, as the first signal intensity peak was higher (Fig. $2 \mathrm{~b}-\mathrm{i}$ and ii). In addition, the curve after the first peak, which represents the permeability-surface area product of the blood vessels, was also higher in MJD mice (Fig. 2b - iii). Furthermore, the final part of the curve revealed the accumulation of the contrast agent in the cerebellar interstitium of transgenic animals (Fig. 2b - iv). All measurements were performed in a selected ROI, defined in the cerebellum.

Overall, MJD transgenic mice showed a 13-fold significant increased perfusion, vascular permeability and interstitial accumulation of contrast agent in the cerebellum as compared to wild-type animals $(0.30 \pm 0.54$ a.u. in wild-type, $n=7$ versus $4.05 \pm 1.48$ a.u in MJD, $n=6$; unpaired t test, $P=0.05$ ), as it is shown by an augmented AUC (Fig. 2c). This result reveals that more contrast agent has passed through blood capillaries and accumulated in the cerebellar interstitium of transgenic animals, in comparison to wild-type animals, due to increased BBB permeability.

\section{Fibrinogen extravasation in the cerebellum of MJD transgenic mice}

EB experiment and DCE-MRI had demonstrated an increased permeability of cerebellar blood vessels in MJD mice. Assessment of extravascular fibrinogen in brain parenchyma can bring further evidence of extravasation of endogenous molecules, in this case, proteins. Therefore, we measured the levels of extravascular fibrinogen, a blood-borne protein that, similarly to albumin, crosses the brain blood vessels in higher levels when BBB is compromised [72]. Extravascular fibrinogen in the cerebellum of animals was assessed by performing co-immunofluorescence with CoIV, a protein of the endothelial basement membrane and a commonly-used marker of blood vessels. Fibrinogen extravasation was observed in the whole cerebellum of 16-17.5-month-old MJD transgenic mice, being however more evident in DCN and lobules 8 and 9, similar with EB staining, as shown in Fig. 3a and b. Extravascular fibrinogen in the cerebellum was quantified by measuring the percentage of surface area positive for fibrinogen staining outside blood vessels (yellow color - Fig. 3c). Overall, a 2fold increase in the extravascular fibrinogen deposition was observed in the cerebellum of MJD transgenic mice as compared to controls $(0.67 \pm 0.15 \%$ in wild-type, $n=4$ vs $1.45 \pm 0.24 \%$ in MJD, $n=4$; unpaired t test, $P=0.03$ ) (Fig. $3 \mathrm{c}$ and $\mathrm{d}$ ). In younger animals (8-weeks old), we also found a tendency for increased levels of fibrinogen extravasation in transgenic mice $(0.033 \% \pm 0.01, n=6$ in wild-type versus $1.04 \% \pm 0.39, n=4$ in transgenic; unpaired t test, $P=$ 0.08). This suggests that BBB disruption is probably an early event in MJD (Supplementary Fig. 2).

Moreover, we measured CoIV surface area to evaluate blood vessels density. It revealed a $16 \%$ higher surface area for CoIV in the cerebellum of 16-17.5-month-old MJD mice comparing to wild-type littermates (19.11\% \pm 1.03, $n=9$ wild-type versus $22.68 \pm 0.93, n=6$ MJD mice, unpaired t test, $P=0.03$ ), suggesting a slight increase in vessels density (Fig. 3e and f).

These results corroborate the data from EB experiment and DCE-MRI, suggesting that the BBB is compromised in MJD allowing blood-borne proteins, namely fibrinogen, to access the cerebellar parenchyma. 

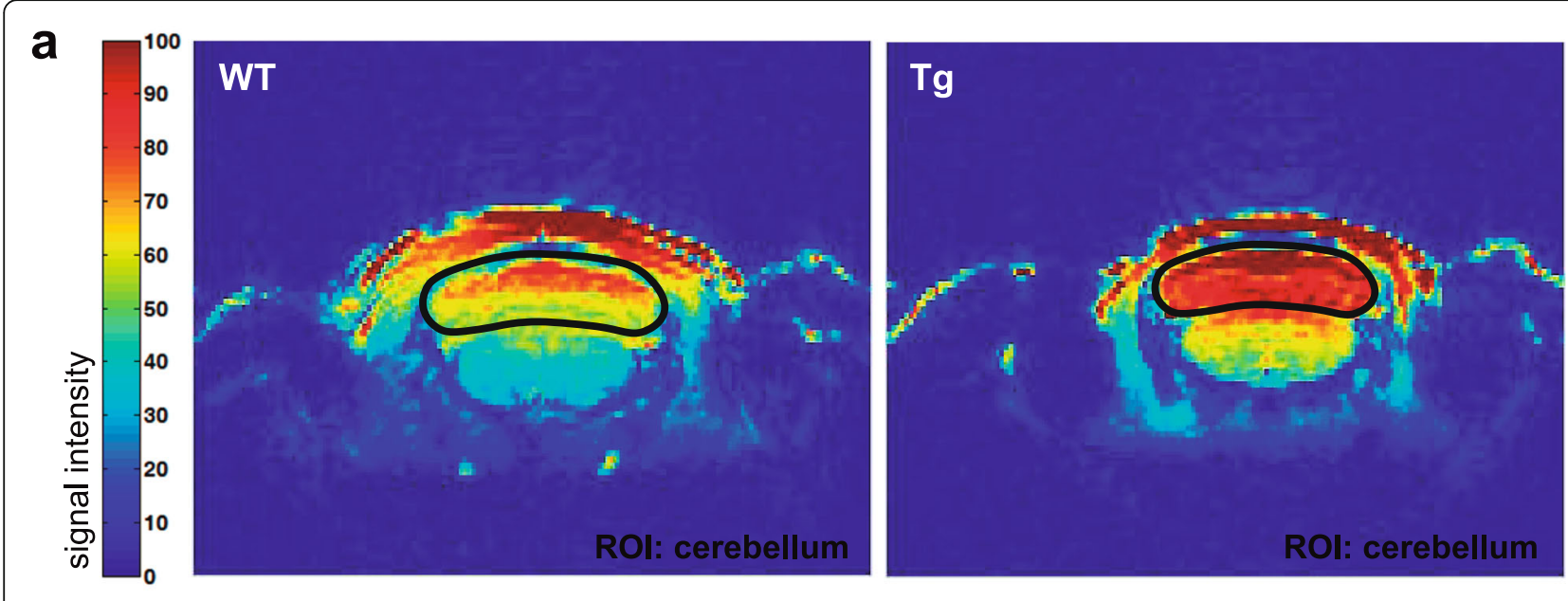

b

Perfusion and vascular permeability in the cerebellum

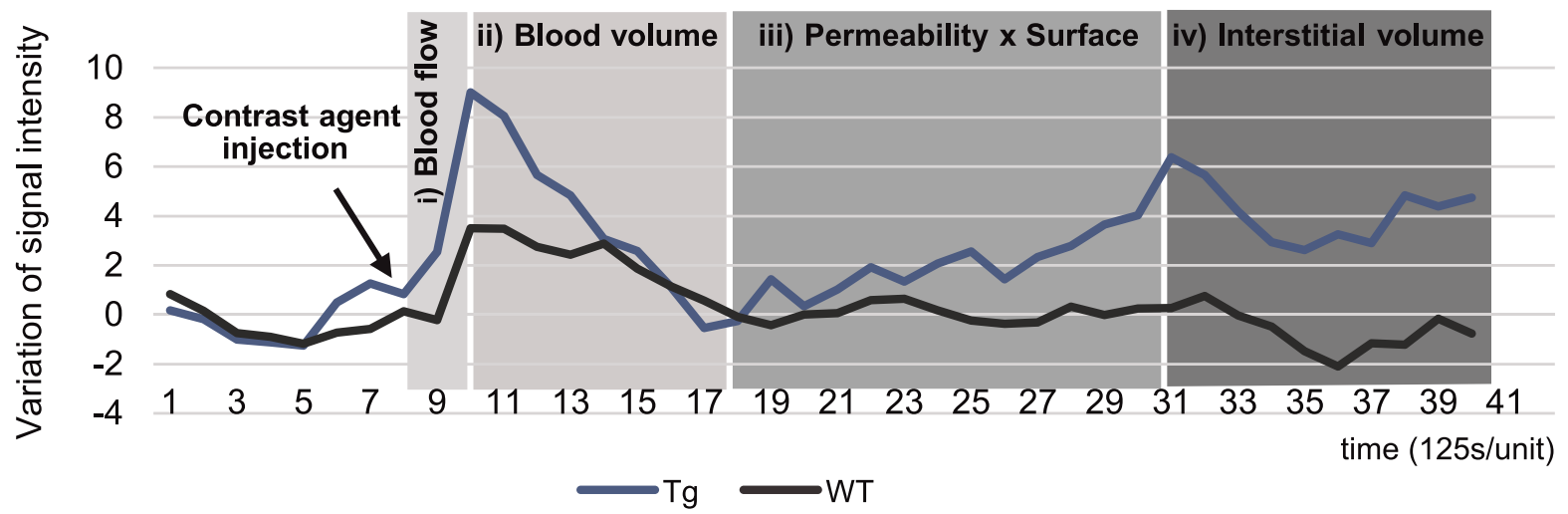

C

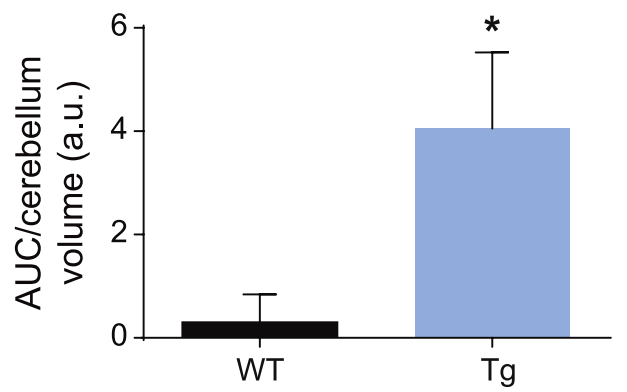

Fig. 2 in vivo evidence of alterations in vascular permeability in MJD transgenic mice using DCE-MRI. a Representative DCE-MRI images, acquired with a fat-saturated T1-weighted gradient-echo sequence, of the cerebellum of a wild-type and a transgenic mouse, respectively; signal intensity scale is given on the left side of the image. $\mathbf{b}$ Group average tissue enhancement curve produced by the contrast agent in the plasma and in the tissue interstitium using DCE-MRI (6 transgenic, Tg; 7 wild-type, WT). MJD transgenic mice showed higher perfusion (i) and cerebellar blood volume (ii), as well as an increased capillary permeability (iii) and contrast agent accumulation in the cerebellum interstitium (iv), as compared to wild-type controls. Each time unit in the graph corresponds to $125 \mathrm{~s}$, the scan time per dynamic acquisition. c Quantification of total tissue enhancement produced by the circulation of contrast agent in the plasma and in the interstitium, here represented as the AUC in arbitrary units (a.u.), showed a 13-fold increase in MJD mice (Unpaired t test, $P=0.05$ ). Unpaired t test with Welch's correction, ${ }^{*} P \leq 0.05$ 


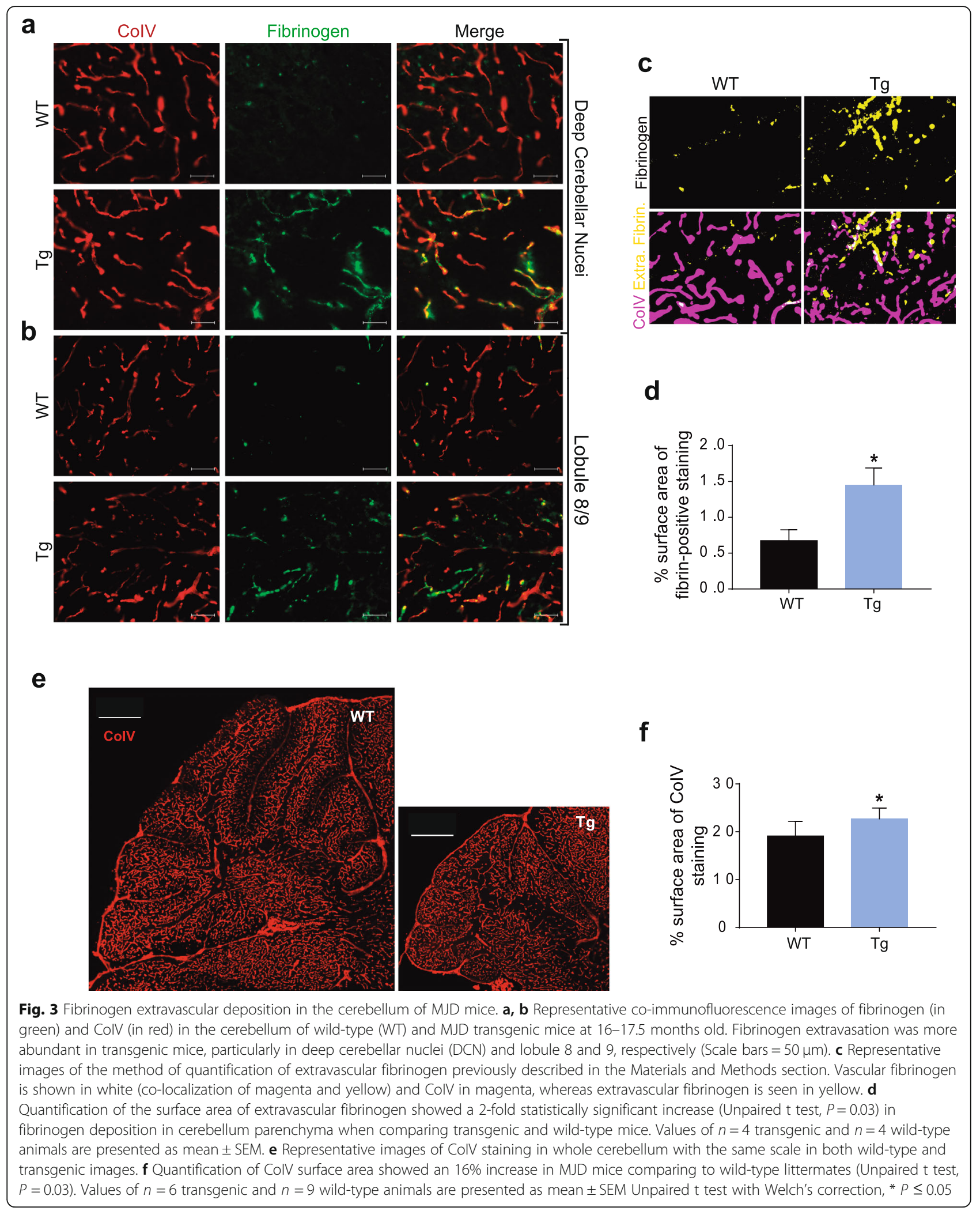




\section{Ataxin-3 aggregates co-localize with cerebellar blood vessels in MJD transgenic mice}

Given the evidence of BBB impairments in the cerebellum of the transgenic animal model used in this study, we next aimed at assessing the presence of mutant ataxin-3 aggregates within cerebellar blood vessels. It is well documented that ataxin-3 aggregates are one of the hallmarks of MJD and, as a consequence, they might interfere directly with BBB function in this disease. To assess this, we performed a co-immunofluorescence assay in MJD transgenic mice. Antibodies against HA, the epitope present in the transgene codifying for expanded ataxin-3, and CoIV were used (Fig. 4a).

Confocal microscopy showed co-localization of mutant ataxin-3 aggregates (HA staining, green) and CoIVpositive blood vessels (red) (Fig. 4b and c). Interestingly, the co-localization of mutant ataxin-3 aggregates within cerebellar blood vessels was particularly evident in the same cerebellar regions where EB (Fig. 1d and e) and fibrinogen (Fig. 3a and b) extravasation was more evident, i.e. in DCN (Fig. 4b) and in lobule 9 (Fig. 4c) of transgenic mice.

Therefore, we identified for the first time the presence of mutant ataxin-3 aggregates in cerebellar blood vessels of MJD mice.

\section{Dysregulation of TJ-associated proteins in the cerebellum of MJD mice}

Considering the alterations in BBB permeability, evidenced by the previous results, and the critical role of
TJs between adjacent endothelial cells for BBB normal functionality, we aimed at elucidating whether BBB disruption was associated with alterations in the levels of TJ-associated proteins. TJs complexes are constituted by transmembrane adhesion proteins, such as claudin-5 and occludin, and cytoplasmic proteins like ZO-1, which attach the transmembrane adhesion proteins to the actin cytoskeleton [67]. The structure of both occludin and claudins exhibits four transmembrane domains and $\mathrm{N}$ and C-termini located in the cytoplasm. The C-terminal domain provides the binding site for several cytoplasmic proteins, such as $\mathrm{ZO}$ proteins, while incorporation of oligomers of proteins such as occludin, claudin- 5 in the intercellular cleft between adjacent cells, maintain TJs integrity $[11,41]$ (Fig. 5a). To evaluate the levels of TJassociated proteins, cerebellar protein extracts of the cerebellum of 16-17.5-month-old mice were analyzed by western blotting with antibodies for the proteins $\mathrm{ZO}$ 1, occludin, claudin-5 and CD31 (Fig. 5b).

The transmembrane protein occludin has a molecular weight of about $63 \mathrm{kDa}$, however fragments with lower molecular weight have been described [4, 23]. Western blotting analysis revealed no significant differences in the relative levels of occludin full form $(63 \mathrm{kDa})$ between MJD transgenic and wild-type animals (Fig. 5c). Nonetheless, a band corresponding to an occludin fragment of $55 \mathrm{kDa}$ (detected with an antibody against the Cterminal region of the protein) was detected in the cerebellum of MJD mice, while barely detected in wild-type animals (Fig. 5b), suggesting that occludin probably
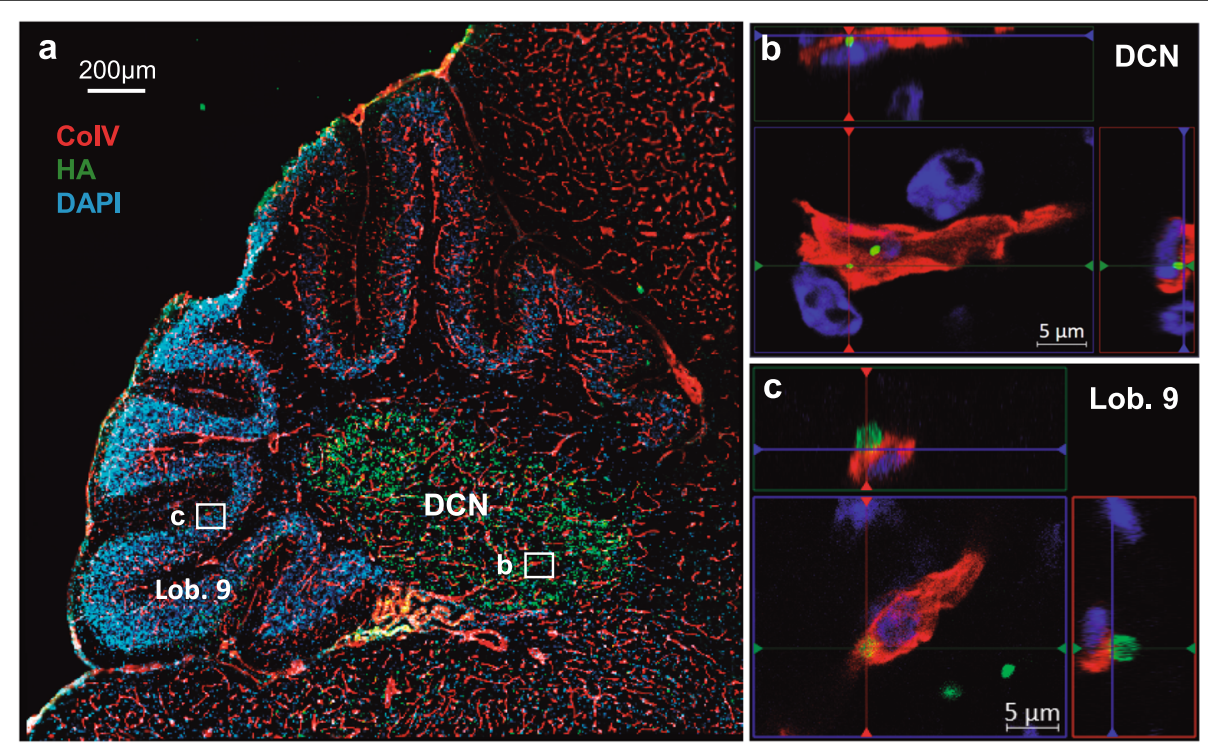

Fig. 4 Co-localization of mutant ataxin-3 aggregates with cerebellar blood vessels of MJD transgenic mice. a Representative coimmunofluorescence images for mutant ataxin-3 aggregates ( $\mathrm{HA}=$ hemagglutinin in green) and CoIV (CoIV = collagen IV in red), confirming the presence of mutant ataxin-3 aggregates within ColV-positive cerebellar blood vessels (Scale bar $=200 \mu \mathrm{m}$ ). In $\mathbf{b}$ and $\mathbf{c}$, ataxin-3 aggregates are shown in blood vessels of deep cerebellar nuclei (DCN) and of lobule 9, respectively. The images are representative of a group of 7 transgenic animals (Scale bars $=5 \mu \mathrm{m}$ ) 


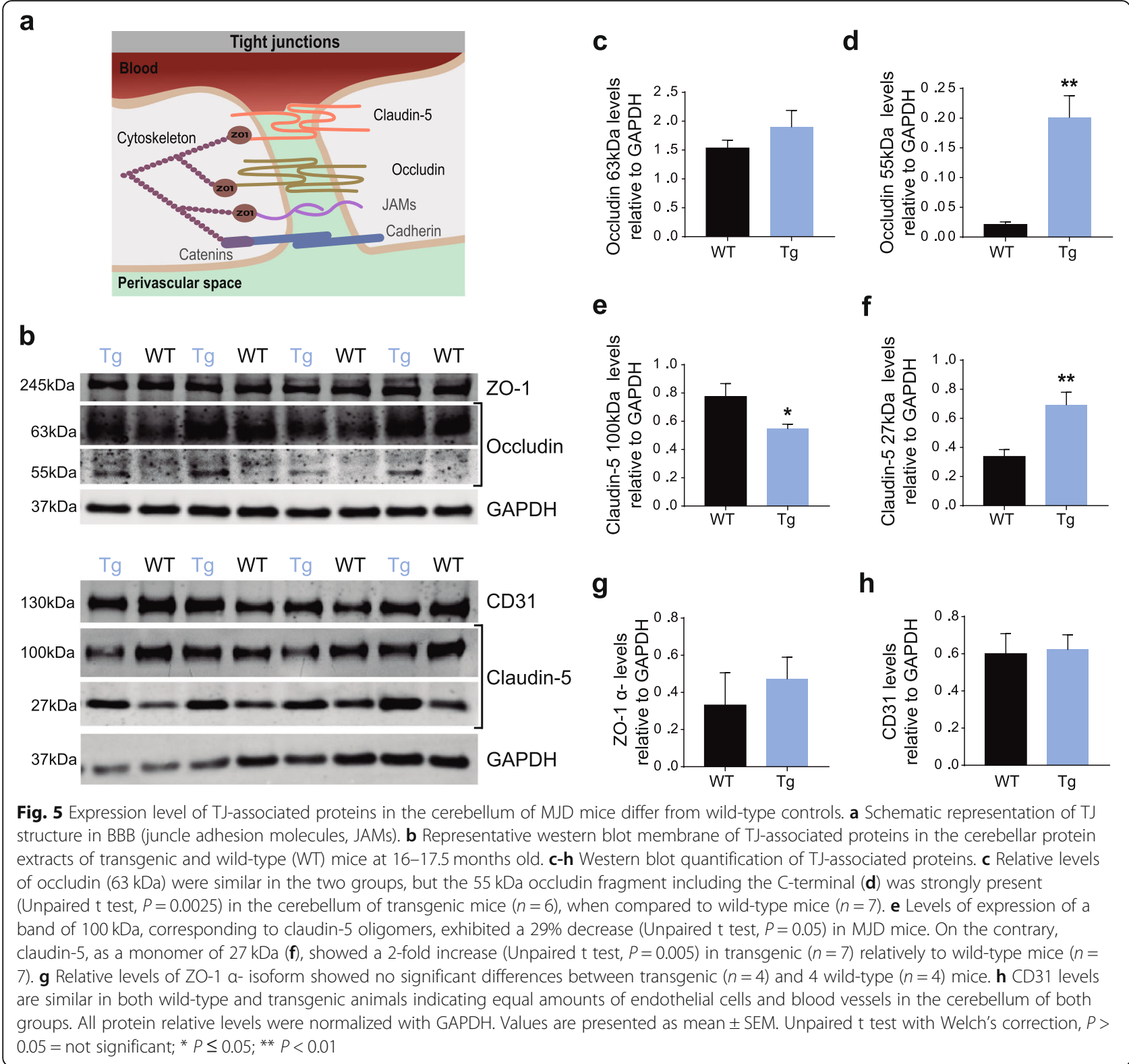

suffers exaggerated cleavage in MJD animals. Upon quantification, the relative levels of this occludin fragment $(55 \mathrm{kDa})$ were 10 times significantly higher in transgenic animals when compared to age-matched controls $(0.021 \pm 0.0044$ in wild-type, $n=7$ versus $0.20 \pm$ 0.036 in MJD, $n=7$; unpaired t test, $P=0.0025$ ) (Fig. $5 \mathrm{~d}$ ). Likewise, when we used an antibody recognizing the $\mathrm{N}$ terminal region of the protein in the same group of mice, the results were similar. In fact, a fragment of 45 $\mathrm{kDa}$ demonstrated an approximately 2 -fold increase in MJD mice comparing to the control group $(0.45 \pm 0.083$ in wild-type, $n=7$ versus $0.83 \pm 0.089$ in MJD; $n=7$; unpaired t test, $P=0.008$ ) (Supplementary Fig. $2 \mathrm{a}$ and $\mathrm{b}$ ), while the $55 \mathrm{kDa}$ band was not detected when using this antibody. This result corroborates the hypothesis of occludin cleavage in the cerebellum of MJD mice.

Claudins are the major players of TJs in the regulation of paracellular permeability in brain endothelial cells, which depends on its oligomerization at the membranes of adjacent cells [3]. Interestingly, in cerebellar protein extracts from MJD mice, a $100 \mathrm{kDa}$ band of Claudin-5 demonstrated a $29 \%$ decrease in comparison to wildtype animals $(0.77 \pm 0.092$ in wild-type, $n=7$ versus $0.55 \pm 0.032$ in MJD, $n=7$; unpaired t test, $P=0.05$ ) (Fig. $5 e)$. This band corresponds to claudin- 5 oligomers that are formed in association with cytoskeleton and membrane, supporting TJs [41]. On the contrary, levels of a $27 \mathrm{kDa}$ monomer of claudin-5, exhibited a 2-fold 
increase in MJD transgenic mice when compared to wild-type animals $(0.34 \pm 0.047$ in wild-type, $n=7$ vs $0.69 \pm 0.087$ in MJD, $n=7$; unpaired $t$ test, $P=0.005$ ) (Fig. 5f). The decline of claudin-5 oligomers in MJD mice may impair its functional role within the TJ architecture. Regarding ZO-1 isoform $\alpha^{-}$, present in the brain endothelium, thus present in BBB, no significant differences were found (Fig. 5g) [70]. These results suggest that ZO-1 protein expression in BBB is not affected in MJD mice. Finally, levels of CD31, often mentioned as an endothelial cell marker, were identical in both groups (Fig. 5h), discarding differences in the extent of cerebellum endothelium/capillaries.

In conclusion, we found evidence of abnormal cleavage of occludin and defects in claudin-5 oligomerization. Overall, these results demonstrate that there are significant differences in the levels and structure of TJassociated proteins in the cerebellum of MJD mice.

\section{Impairment of BBB in post-mortem human tissue from MJD patients}

Since we have found evidence of BBB impairments in MJD mice, we further evaluated how these findings translated to the human disease. Therefore, fibrinogen extravasation across BBB and the presence of ataxin-3 aggregates in human brain blood vessels were assessed by immunofluorescence analysis of human post-mortem fixed tissue of MJD patients and control individuals.

Antibodies against CoIV (red) and fibrinogen (green) were used to quantify the surface area of extravascular fibrinogen, as previously described for mouse tissue. Images obtained with confocal microscopy showed augmented fibrinogen outside the CoIV-positive blood vessels in MJD patients in comparison with control samples (Fig. 6a). Furthermore, quantification of the relative surface area of extravascular fibrinogen revealed that all MJD samples analyzed showed increased fibrinogen extravasation in relation with control individuals (Fig. 6b), also emphasizing our previous results in MJD mice.

In contrast with MJD mice, human striatum sections showed no differences between CoIV surface area between patients and control individuals (Fig. 6c). This result suggests that blood vessels density is maintained in the disease.

To assess the localization of ataxin-3 aggregates, coimmunofluorescence with antibodies against CoIV (blood vessel marker, red) and ataxin-3 (1H9 epitope, green) was performed. Confocal microscopy revealed colocalization of CoIV and ataxin-3 protein, as shown by the overlap of red and green, indicative of the presence of expanded ataxin-3 aggregates within brain blood vessels in the three MJD patients (Fig. 6d).

To investigate whether BBB impairment was associated with neuroinflammation and, specifically to astrogliosis and microgliosis, we carried out immunohistochemistry against CoIV (blood vessels marker), GFAP (astrocyte marker) and Iba1 (microglia marker) in striata tissue from MJD patients and control individuals. We observed an increase in reactive microglia, as shown in representative images of MJD patient's striata (Fig. 6e). The microglial marker, Iba1, displayed an approximately 2-fold increase (from 0.87 a.u. $\pm 0.021, n=2$ to 1.48 a.u. $\pm 0.055, n=3$ in MJD patients, $P=0.004$, Fig. 6 f), while GFAP levels did not show apparent differences between patients and healthy individuals (Fig. 6g). Interestingly, microglia appear to be recruited to blood vessels, as it is suggested by the proximity of CoIV (red) with Iba1 marker (green, Fig. 6e).

In conclusion, and similarly to the investigated MJD mouse model, we found evidence of extravasation of fibrinogen and the presence of ataxin-3 aggregates in brain blood vessels of MJD patients that further support the impairment of BBB as part of the MJD neuropathology. Moreover, here we confirm that neuroinflammation is a neuropathological event that is concomitant with BBB dysregulation in MJD.

\section{Discussion}

Despite the substantial work already done in understanding BBB influence and cerebrovascular network alterations in neurodegenerative disorders, to our knowledge, this is the first study that evaluates the BBB integrity in spinocerebellar ataxias and particularly in MJD. In this work, we found increased blood brain vessels permeability, demonstrated by different techniques in a mouse model of MJD and in patients' samples, accompanied by the presence of ataxin-3 aggregates in brain capillaries. Alterations in TJ-associated proteins levels were also identified in MJD mice, as a plausible cause of $\mathrm{BBB}$ structural disintegration. Such impairment of BBB may contribute to disease progression and clinical manifestations. In this study, we made use of the transgenic mouse model of MJD previously developed by Torashima and collaborators that expresses a truncated form of human ataxin-3 with 69 CAG mostly in Purkinje cells of the cerebellum [65]. This represents an advantage of the model, since there is a defined brain region in which the disease is developed and where the BBB might be disrupted. EB assay showed that in this animal model, EB dye was significantly increased in the cerebellum parenchyma as compared to wild-type controls. However, no significant differences were found in the cerebrum of transgenic animals. This provides clear evidence that transgene expression (mutant ataxin-3) is the trigger to $\mathrm{BBB}$ disruption, since the brain region where mutant ataxin-3 is almost exclusively expressed in adult mice (i.e. cerebellum) corresponds to the region of increased vascular permeability. 


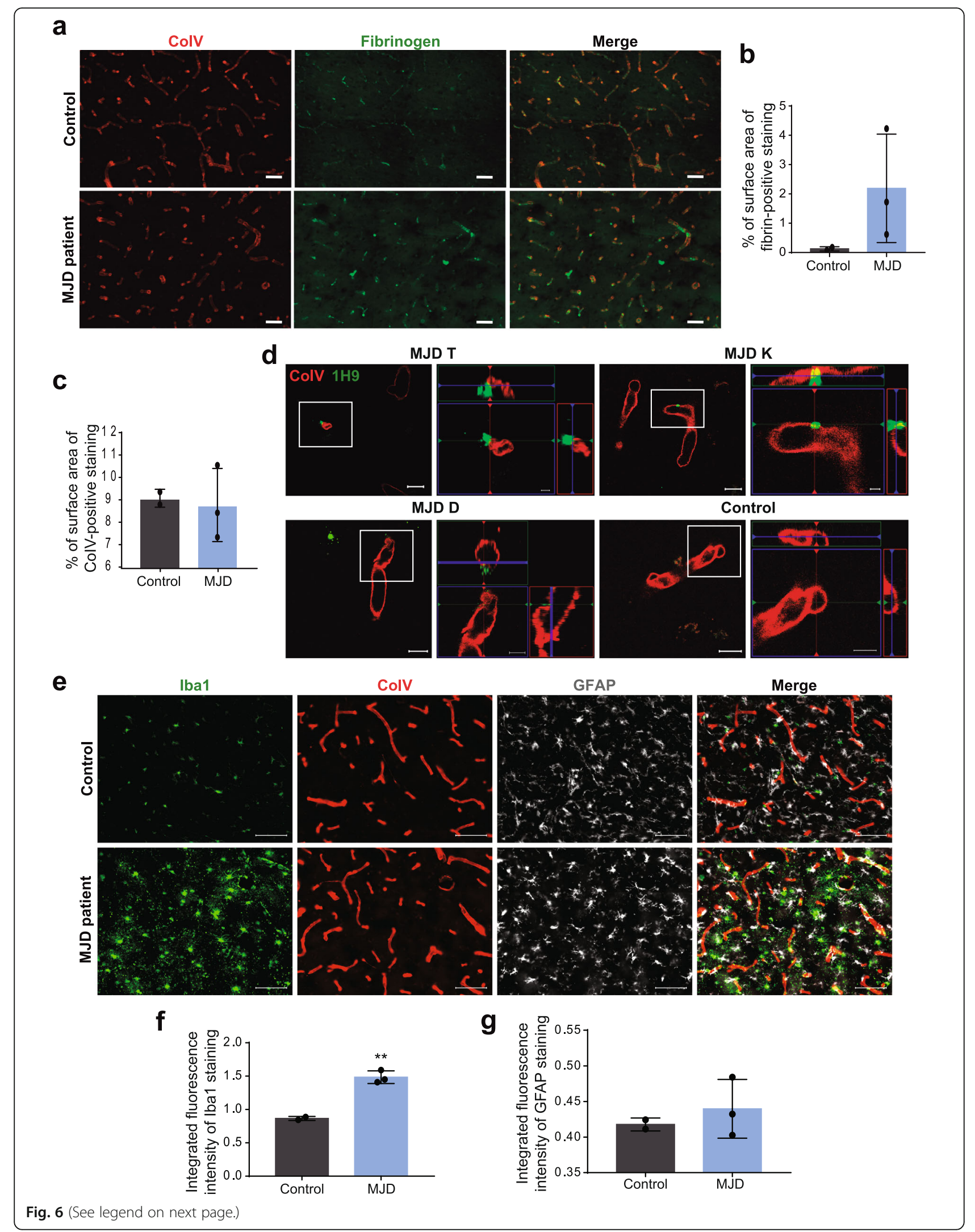




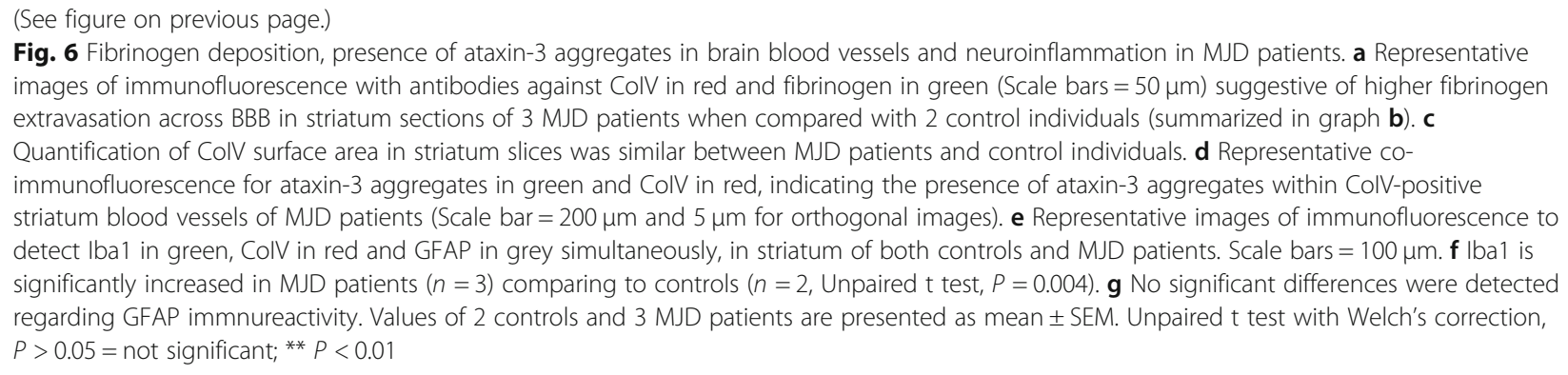

BBB impairment in this animal model was further supported by DCE-MRI, a non-invasive method useful to evaluate BBB in vivo even in small animals [9]. Upon injection of a contrast agent, the variation in signal intensity produced by its circulation in the bloodstream is recorded through a dynamic acquisition. The signal reaches a peak and then decreases at a rate that is slower in conditions of a leaky BBB due to the accumulation of the contrast agent in the brain parenchyma. Accordingly, MJD transgenic mice displayed increased cerebellar blood volume and higher vascular permeability. DCEMRI has been used to evaluate BBB permeability associated, for instance, with brain tumors and cerebral artery occlusion in small animals, however its application in animal models of neurodegenerative diseases is recent [5, 20, 29, 32]. Even though, Ikawa and colleagues reported decreased cerebellar blood flow in MJD patients upon arterial spin-labelling, these authors did not evaluate vascular permeability. Therefore, further studies with DCE-MRI are needed to confirm or not BBB leakage in MJD patients [26].

In accordance with the previous results, higher levels of extravascular fibrinogen were observed in MJD mice cerebella. Results of younger mice suggest BBB opening in an early stage that progresses to substantial BBB leakage in older animals. Similarly, all MJD patients' samples analyzed also revealed increased fibrinogen extravasation across striatal blood vessels relative to controls, which once again evidenced BBB disruption in this disease. According to the literature, the extension of $\mathrm{BBB}$ permeability differs among brain regions, so cerebellum and other regions should be assessed in MJD patients [43]. Still, such BBB opening is probably substantial, given that the molecular weight of fibrinogen and its fragments range from 60 to $340 \mathrm{kDa}$. Therefore, that might be the reason why differences in younger animals were not statistically significant [68]. In order to clarify BBB integrity at an earlier disease stage, more sensitive methods should be explored, to identify minor BBB alterations. The penetration of both albumin (bound to EB) and fibrinogen in the brain parenchyma may occur by the paracellular route of brain endothelial cells, whose regulation is assured mainly by TJs, discussed below. However, transcellular transport, namely transcytosis, can also be dysregulated in this mouse model since large proteins can overcome BBB by this route $[54,66]$. Therefore, future studies should evaluate transcytosis, as $\mathrm{BBB}$ could be dysfunctional at the paracellular and transcellular levels, as reported for Huntington's disease [13]. More than a marker for BBB disruption, fibrinogen plays a significant role in neuroinflammation, which was demonstrated here by the significant enhancement of microglia activation in MJD patients, and contributes to neuronal loss [57]. In neurodegenerative diseases bearing BBB alterations, such as Alzheimer's, Huntington's, Parkinson's disease, Multiple sclerosis and Amyotrophic lateral sclerosis, fibrinogen deposition has been correlated with degeneration of the neurovascular unit components, including pericytes [13, 22, 25, 30]. Moreover, fibrinogen extravasation has been associated with cerebral amyloid angiopathy, in which amyloid accumulates mostly in blood vessels [37]. In many of these diseases, fibrinogen deposition outside brain blood vessels is accompanied by alterations in TJs, also demonstrated here in MJD mice.

Altogether, our results show BBB malfunction in MJD, allowing blood-borne proteins, namely albumin and fibrinogen, to abnormally access the cerebellum. Both EB and fibrinogen extravasation across cerebellar blood vessels were more evident in DCN of mice, a region of the cerebellum with enhanced accumulation of ataxin-3 aggregates in this MJD mouse model. This suggested a direct relation between the presence of aggregates and BBB disruption. Mutant ataxin-3 aggregates were found to be present in cerebellar blood vessels, suggesting that mutant ataxin-3 may have a direct impact in BBB disruption. Similarly, the presence of expanded ataxin-3 aggregates within blood vessels was confirmed, in the present work, in MJD patients. In another transgenic mouse model of the disease, YAC84Q, ataxin-3 transcripts were found in several cell types, such as oligodendrocytes, astrocytes and microglia and also in endothelial cells. Besides ataxin-3 transcripts, aggregates of this protein were present in oligodendrocytes, driving toxicity in a cell-autonomous manner [44]. The same may occur in MJD patients at the level of BBB- 
associated cells, which would explain endothelial barrier disruption in MJD, as a consequence of the presence of ataxin-3 toxic forms in those cells. Nevertheless, it is plausible to consider that expanded ataxin-3 toxicity is not strictly cell-autonomous, as its aggregates may spread between cells. A similar observation was recently made for Huntington's disease in relation to huntingtin aggregates $[7,13]$. Thus, it remains important to clarify where the aggregates are in brain blood vessels of MJD mice (i.e. inside endothelial cells, pericytes, at the extracellular space or even in all these locations). Still, mutant ataxin-3 aggregates within blood vessels may promote vascular disarrangements in the brain of MJD transgenic mice and patients. In fact, as previously mentioned, mutant ataxin-3 is known to trigger neuroinflammation, disturb mitochondria function, dysregulate autophagy and interfere with calcium homeostasis, which are also some of the pathological mechanisms known to interfere with brain endothelial cells and affect the TJs function [6, 28, 34, 42, 50].

Given the importance of TJs in brain endothelial cells, we assessed the relative levels of occludin, claudin- 5 and ZO-1 in protein extracts from the cerebellum of transgenic and wild-type mice. Occludin is one of the transmembrane proteins and is constituted by two domains: a long cytoplasmic $\mathrm{C}$-terminal and $\mathrm{N}$-terminal domains [33]. Cerebellar protein extracts did not reveal significant differences in the levels of full-length occludin. However, a $55 \mathrm{kDa}$ fragment of lower molecular weight, was significantly increased in transgenic animals and nearly absent in wild-type controls. According to the literature, this fragment may correspond to the cytoplasmic Cterminal of occludin, lacking a transmembrane domain, which suggests abnormal occludin cleavage in MJD mice [23]. When using an antibody produced to recognize the $\mathrm{N}$-terminal domain of occludin, a single fragment of smaller molecular weight $(45 \mathrm{kDa})$ was detected and significantly increased in MJD mice. The fact that the 55 $\mathrm{kDa}$ fragment was not detected by this antibody indicates that this occludin fragment lacks, at least part, of its $\mathrm{N}$-terminal. This corroborates occludin cleavage in the endothelial cells of the cerebellum in this MJD mouse model. Interestingly, the N-terminal of occludin has been shown to be essential to TJs assembly in epithelial cells [2]. Similar evidence of occludin fragmentation in the brain were already demonstrated in early ischemic stroke or bacterial meningitis, and associated to matrix metalloproteinase (MMP) activity. Specifically, MMP-2, 8 and 9 were identified as responsible for occludin cleavage $[36,58]$. In fact, it is known that: i) inflammatory responses regulate MMP expression and secretion in the brain [73]; ii) in MJD there is an exacerbated neuroinflammation [18, 19]. Moreover, mutant ataxin-3 leads to MMP2 increased expression [18].
Calpains have also been described to be involved in MJD neuropathology, particularly, in ataxin-3 proteolysis [60]. Like MMPs, calpains were associated with TJs degradation. In CaSki epithelial cells for instance, calpainmediated breakdown of occludin led to the increase of a fragment with $50 \mathrm{kDa}$ that interfered with $\mathrm{TJ}$ assembly, similarly to our results [74]. Based on that, it is plausible that occludin fragments observed in this transgenic mouse model may be explained by increased proteases activity, such as MMPs or calpains. Further assessments will be needed to answer these fundamental questions.

Claudin-5 is another transmembrane protein essential for the TJ assembly in brain endothelial cells. In neurodegenerative disorders involving BBB dysfunction, such as Huntington's and Alzheimer's disease, this TJassociated protein undergoes decrease of expression or redistribution $[13,38]$. In the cerebellum of MJD mice that were analyzed in the present study by western blotting, the antibody used labeled an oligomer form of claudin-5 $(100 \mathrm{kDa})$ which showed to be decreased comparing to wild-type animals. In contrast, the claudin- 5 monomer of $27 \mathrm{kDa}$ was significantly increased. Given that claudin-5 assembly into oligomers allows the proper arrangement of TJs structure at cellular membrane, these results suggest that the increment in claudin- 5 monomer is not translated in the oligomerization of the protein at the membrane, which may contribute to disruption of the BBB in MJD $[8,41]$. The increment in the expression of claudin -5 as a compensatory mechanism due to occludin degradation has been proposed in other neurodegenerative disorders with $\mathrm{BBB}$ dysfunction, though its redistribution from the membrane to the cytoplasm did not preserve BBB integrity [21, 35, 36]. Similarly to occludin, claudin -5 has been described to be susceptible to the action of MMPs, as it was observed in an in vitro model of Alzheimer's disease [31, 62, 69]. Another explanation for claudin-5 alterations in MJD mice is associated with autophagy. It has been shown in cell lines from cerebral endothelium, that autophagy is critical to a correct claudin- 5 distribution at the membrane and, consequently, to assure endothelium properties [71]. Since MJD is associated with autophagy impairments, this can explain, at least in part, the decrease in claudin-5 oligomers even when there is an increase in the monomer observed in our MJD transgenic model $[45,50]$. Moreover, based on the fact that TJs are associated with cholesterol-rich lipid domains at the membrane, alterations in claudin- 5 oligomerization in MJD might be related to cholesterol, since a deregulation in brain cholesterol metabolism was recently demonstrated in MJD [47]. It would also be relevant to evaluate other claudins, for instance claudin-1 and -25 , since they also play a significant role in maintaining paracellular tightness and TJs formation [3]. 
Neuroinflammation is already an accepted neuropathological event in MJD. In a large cohort of MJD patients, the serum levels of GFAP were found to be augmented when compared to healthy individuals [59]. Moreover, increased expression of cytokines, such as interleukins $1 \beta$ and 6 , has been found in neurons from the pons and dentate nucleus $[17,18]$. Over the years, our group has demonstrated that neuroinflammation is indeed present both in lentivirus-based mouse model and in the transgenic mouse model of MJD herein used and that efficient therapeutic strategies also act by reducing the levels of neuroinflammation mediators [24, 42]. Neuroinflammation is also a major player in neurodegenerative disorders bearing $\mathrm{BBB}$ alterations. It has been demonstrated the recruitment of microglia to injured blood vessels, which was also observed here in the striatum of MJD patients. Consequently, reactive microglia exacerbates brain tissue damage [14]. In MJD, neuroinflammation can be a cause of BBB disruption, which in turn might lead to further inflammation. Indeed, the monogenic nature of MJD suggests that BBB dysfunction may be a secondary event [27]. However, the question of when $\mathrm{BBB}$ disruption starts along disease progression still remains. This question of event sequence regarding BBB in brain disorders is controversial. For instance, in a mouse model of Alzheimer's disease, BBB dysfunction was demonstrated only in a late stage. Increased brain vascular permeability in mice was shown by the same technique herein used, DCE-MRI, revealing BBB permeability after 16 months of age [5]. On the other hand, a study in human cognitive dysfunction proved BBB alterations as an early biomarker of the disease [46]. In MJD, expanded ataxin-3 expression and resulting neuropathology, including autophagy impairments, mitochondria dysfunction, transcriptional dysregulation and others, may influence BBB indirectly, by interfering with the neurovascular coupling, pointing to the need to evaluate other components of the neurovascular unit, such as pericytes. Besides that, the presence of aggregates in blood vessels suggests a direct relation of mutant ataxin3 with BBB. Mutant ataxin-3 is known to disturb several cellular mechanisms in neurons, and if the same occurs in brain endothelial cells, this can explain the alterations in TJs seen here. Further studies are necessary to better understand the contribution of BBB disruption to MJD progression.

\section{Conclusions}

Given the essential role of BBB in maintaining homeostasis, its dysfunction possibly exacerbates MJDassociated neuropathological events, such as neuroinflammation. BBB dysregulation may be a major contributor to neurodegeneration in MJD by, for instance, allowing circulating leukocytes to migrate through the
BBB, which will intensify inflammation producing severe tissue damage [13, 52, 53]. Alterations on BBB function might even contribute to disease onset, as it is accepted for other neurodegenerative diseases [44].

This work shows for the first time that the BBB is impaired in MJD, a relevant information both for the knowledge of the disease, as well as for the development of a potential biomarker of disease progression with therapeutic relevance. Importantly, from a pharmacological perspective, an increased BBB permeability can also be seen as an opportunity to use therapeutic agents that until now were thought to be unable to cross brain blood vessels.

\section{Supplementary information}

Supplementary information accompanies this paper at https://doi.org/10. 1186/s40478-020-00955-0.

Additional file 1: Supplementary Table 1. Additional pathological
data summary of analyzed postmortem tissue from patients
Additional file 2: Supplementary Results. Figure 1. Ratio of EB
concentrations in the cerebrum and cerebellum when normalized with
EB concentration in the liver in WT and MJD mice. a Ratio of EB
concentrations in the cerebrum and in the liver in wild-type and trans-
genic animals. b Ratio of EB concentrations in cerebellum and liver of this
dye in wild-type and transgenic mice. Values are presented as mean \pm
SEM. Unpaired t-test, $p>0.05=$ not significant and *** $p<0.001$. Figure 2.
Fibrinogen extravascular deposition in the cerebellum of 8 -week old MJD
mice. a Representative co-immunofluorescence images of fibrinogen (in
green) and CoIV (in red) in the cerebellum of wild-type (WT, $n=6,1$ fe-
male and 5 males) and MJD transgenic (Tg, $n=4,3$ females and 1 male)
mice. Fibrinogen extravasation was more abundant in transgenic mice,
particularly in deep cerebellar nuclei (DCN) (Scale bars $=100$ m). b Quan-
tification of the surface area of extravascular fibrinogen showed a ten-
dency for an increased (Unpaired t test, $P=0.08$ ) fibrinogen deposition in
cerebellum parenchyma when comparing transgenic and wild-type mice.
Immunofluorescence and its quantification were performed as described
for older animals. Values are presented as mean \pm SEM. Unpaired t test
with Welch's correction. Figure $\mathbf{3}$. Relative levels of occludin protein in
the cerebellum of MJD mice differs from wild-type controls. a Representa-
tive Western blot membrane of occludin staining with an antibody rec-
ognizing the N-terminus of the protein in cerebellar protein extracts of
transgenic (Tg) and wild-type (WT) mice at $16-17.5$ months old. b West-
ern blot quantification of occludin fragment of $45 \mathrm{kDa}$ in transgenic mice
( $n=7$ ) and wild-type controls ( $n=7$ ). Protein relative levels were normal-
ized with GAPDH. Values are presented as mean $\pm S E M$. Unpaired t-test,
$* * 0<0.01$

\section{Abbreviations}

AUC: Area under the curve; BBB: Blood-brain barrier; CD31: Cluster of differentiation 31; ColV: Collagen type IV; DAPI: 4',6-diamidino-2-phenylindole; DCE-MRI: Dynamic Contrast Enhanced-Magnetic Resonance Imaging; DCN: Deep cerebellar nuclei; EB: Evans blue; GFAP: Glial fibrillary acidic protein; HA: Hemagglutinin; Iba1: Ionized calcium-binding adapter molecule 1; MJD: Machado-Joseph disease; MMP: Matrix metalloproteinase; ROI: Region of interest; SCA: Spinocerebellar ataxia; SCA3: Spinocerebellar ataxia type 3;

TJ: Tight junction; ZO-1: Zonula occludens-1

\section{Acknowledgments}

Not applicable.

\section{Authors' contributions}

DDL processed the animal and human tissues, analyzed the results and wrote the manuscript with the help from RJN and COM. Additionally, RJN and COM performed EB assay and conceptualized and supervised the study. 
DP participated in samples' processing. JC and JS performed and analyzed the DCE-MRI experiment with the help of MCB, who supervised this experiment. AK provided the human brain tissue. LPA supervised the project and acquired the funding. All the authors have read and approved the manuscript.

\section{Authors' information}

Diana Duarte Lobo, Rui Jorge Nobre and Catarina Oliveira Miranda contributed equally to this work.

\section{Funding}

Our group is supported by the European Regional Development Fund through the Regional Operational Program Center 2020, Competitiveness Factors Operational Program (COMPETE 2020) and National Funds through Foundation for Science and Technology (FCT): BrainHealth2020 projects (CENTRO-01-0145-FEDER-000008), ViraVector (CENTRO-01-0145-FEDER022095), CortaCAGs (POCl-01-0145-FEDER-016719), SpreadSilencing POCI-010145-FEDER-029716, Imagene POCI-01-0145-FEDER-016807, CancelStem POCI-01-0145-FEDER-016390, as well as UID4950/2020 (to MCB), BIN - National Brain Imaging Network (CENTRO-01-0145-FEDER-022118) and the Association Française contre les Myopathies -Téléthon no. 21163 and the SynSpread, European SCA3/MJD Initiative and ModelPolyQ under the EU Joint Program, the last two co-funded by the European Union H2O20 program, GA No. 643417; by National Ataxia Foundation, the American Portuguese Biomedical Research Fund and the Richard Chin and Lily Lock Machado-Joseph Disease Research Fund.

\section{Availability of data and materials}

All data generated or analysed during this study are included in this published article [and its supplementary information files].

\section{Ethics approval and consent to participate}

All animal experiments were carried out in accordance with the European Community Council Directive (2010/63/EU) for the care and use of laboratory animals and previously approved by the Responsible Organization for the Animals Welfare of the Faculty of Medicine and Center for Neuroscience and Cell Biology of the University of Coimbra (ORBEA and FMUC/CNC, Coimbra, Portugal).

Tissue from MJD patients and controls was obtained from the Neurology and Pathology Services, VA Medical Center, Albany Medical College, Albany, New York, NY, USA. All donors or their surrogates, had given informed consent for the use of their brain tissue for research purposes in accordance with the medical ethical committee of Albany Medical College, USA.

\section{Consent for publication}

Not applicable.

\section{Competing interests}

The authors declare that they have no competing interests.

\section{Author details}

${ }^{1}$ CNC - Center for Neuroscience and Cell Biology of Coimbra, Molecular Therapy of Brain Disorders Group, University of Coimbra, Rua Larga, 3004-504 Coimbra, Portugal. ${ }^{2} \mathrm{ClBB}$ - Center for Innovative Biomedicine and Biotechnology; Vectors, Gene and Cell Therapy Group, University of Coimbra, 3004-504 Coimbra, Portugal. ${ }^{3}$ III - Institute for Interdisciplinary Research, University of Coimbra, 3030-789 Coimbra, Portugal. ${ }^{4}$ ViraVector - Viral Vector for Gene Transfer Core facility, University of Coimbra, 3004-504 Coimbra, Portugal. ${ }^{5} \mathrm{CIBIT}$ (Coimbra Institute for Biomedical Imaging and Translational Research)/ICNAS - Institute of Nuclear Sciences Applied to Health, 3000-548 Coimbra, Portugal. ${ }^{6}$ iCBR - Coimbra Institute for Clinical and Biomedical Research, University of Coimbra, 3000-548 Coimbra, Portugal. ${ }^{7}$ Departments of Neurology and Pathology, Albany Medical College, Albany, NY, USA. ${ }^{8}$ Veterans Affairs Medical Center, 113 Holland Ave, Albany, NY 12208, USA. ${ }^{9}$ Faculty of Pharmacy, University of Coimbra, 3000-548 Coimbra, Portugal.
Received: 11 April 2020 Accepted: 25 May 2020

Published online: 31 August 2020

\section{References}

1. Alves S, Regulier E, Nascimento-Ferreira I, Hassig R, Dufour N, Koeppen A et al (2008) Striatal and nigral pathology in a lentiviral rat model of MachadoJoseph disease. Hum Mol Genet 17:2071-2083. https://doi.org/10.1093/ hmg/ddn106

2. Bamforth SD, Kniesel U, Wolburg H, Engelhardt B, Risau W (1999) A dominant mutant of occludin disrupts tight junction structure and function. J Cell Sci 112(Pt 12):1879-1888

3. Berndt $P$, Winkler $L$, Cording J, Breitkreuz-Korff $O$, Rex A, Dithmer $S$ et al (2019) Tight junction proteins at the blood-brain barrier: far more than claudin-5. Cell Mol Life Sci 76:1987-2002. https://doi.org/10.1007/s00018019-03030-7

4. Bojarski C, Weiske J, Schoneberg T, Schroder W, Mankertz J, Schulzke JD et al (2004) The specific fates of tight junction proteins in apoptotic epithelial cells. J Cell Sci 117:2097-2107. https://doi.org/10.1242/jcs.01071

5. Chiquita S, Ribeiro M, Castelhano J, Oliveira F, Sereno J, Batista M et al (2019) A longitudinal multimodal in vivo molecular imaging study of the 3XTg-AD mouse model shows progressive early hippocampal and taurine loss. Hum Mol Genet 28:2174-2188. https://doi.org/10.1093/hmg/ddz045

6. Chou AH, Yeh TH, Ouyang P, Chen YL, Chen SY, Wang HL (2008) Polyglutamine-expanded ataxin-3 causes cerebellar dysfunction of SCA3 transgenic mice by inducing transcriptional dysregulation. Neurobiol Dis 31: 89-101. https://doi.org/10.1016/.nbd.2008.03.011

7. Cicchetti F, Lacroix S, Cisbani G, Vallieres N, Saint-Pierre M, St-Amour I et al (2014) Mutant huntingtin is present in neuronal grafts in Huntington disease patients. Ann Neurol 76:31-42. https://doi.org/10.1002/ana.24174

8. Coyne CB, Gambling TM, Boucher RC, Carson JL, Johnson LG (2003) Role of claudin interactions in airway tight junctional permeability. Am J Physiol Lung Cell Mol Physiol 285:L1166-L1178. https://doi.org/10.1152/ajplung. 00182.2003

9. Cuenod CA, Balvay D (2013) Perfusion and vascular permeability: basic concepts and measurement in DCE-CT and DCE-MRI. Diagn Interv Imaging 94:1187-1204. https://doi.org/10.1016/j.diii.2013.10.010

10. Cunha-Santos J, Duarte-Neves J, Carmona V, Guarente L, Pereira de Almeida L, Cavadas C (2016) Caloric restriction blocks neuropathology and motor deficits in Machado-Joseph disease mouse models through SIRT1 pathway. Nat Commun 7:11445. https://doi.org/10.1038/ncomms11445

11. D'Atri F, Citi S (2002) Molecular complexity of vertebrate tight junctions (review). Mol Membr Biol 19:103-112. https://doi.org/10.1080/ 09687680210129236

12. do Carmo Costa M, Bajanca F, Rodrigues AJ, Tome RJ, Corthals G, MacedoRibeiro $S$ et al (2010) Ataxin-3 plays a role in mouse myogenic differentiation through regulation of integrin subunit levels. PLoS One 5 e11728. https://doi.org/10.1371/journal.pone.0011728

13. Drouin-Ouellet J, Sawiak SJ, Cisbani G, Lagace M, Kuan WL, Saint-Pierre M et al (2015) Cerebrovascular and blood-brain barrier impairments in Huntington's disease: potential implications for its pathophysiology. Ann Neurol 78:160-177. https://doi.org/10.1002/ana.24406

14. Dudvarski Stankovic N, Teodorczyk M, Ploen R, Zipp F, Schmidt MHH (2016) Microglia-blood vessel interactions: a double-edged sword in brain pathologies. Acta Neuropathol 131:347-363. https://doi.org/10.1007/s00401015-1524-y

15. Ellisdon AM, Thomas B, Bottomley SP (2006) The two-stage pathway of ataxin-3 fibrillogenesis involves a polyglutamine-independent step. J Biol Chem 281:16888-16896. https://doi.org/10.1074/jbc.M601470200

16. Evert BO, Araujo J, Vieira-Saecker AM, de Vos RA, Harendza S, Klockgether T et al (2006) Ataxin-3 represses transcription via chromatin binding, interaction with histone deacetylase 3 , and histone deacetylation. J Neurosci 26:11474-11486. https://doi.org/10.1523/JNEUROSCI.2053-06.2006

17. Evert BO, Schelhaas J, Fleischer H, de Vos RA, Brunt ER, Stenzel W et al (2006) Neuronal intranuclear inclusions, dysregulation of cytokine expression and cell death in spinocerebellar ataxia type 3. Clin Neuropathol 25:272-281

18. Evert BO, Vogt IR, Kindermann C, Ozimek L, de Vos RA, Brunt ER et al (2001) Inflammatory genes are upregulated in expanded ataxin-3-expressing cell lines and spinocerebellar ataxia type 3 brains. J Neurosci 21:5389-5396

19. Evert BO, Vogt IR, Vieira-Saecker AM, Ozimek L, de Vos RA, Brunt ER et al (2003) Gene expression profiling in ataxin-3 expressing cell lines reveals 
distinct effects of normal and mutant ataxin-3. J Neuropathol Exp Neurol 62: 1006-1018

20. Ferrier MC, Sarin H, Fung SH, Schatlo B, Pluta RM, Gupta SN et al (2007) Validation of dynamic contrast-enhanced magnetic resonance imagingderived vascular permeability measurements using quantitative autoradiography in the RG2 rat brain tumor model. Neoplasia 9:546-555. https://doi.org/10.1593/neo.07289

21. Fiorentino M, Sapone A, Senger S, Camhi SS, Kadzielski SM, Buie TM et al (2016) Blood-brain barrier and intestinal epithelial barrier alterations in autism spectrum disorders. Mol Autism 7:49. https://doi.org/10.1186/s13229016-0110-z

22. Garbuzova-Davis S, Hernandez-Ontiveros DG, Rodrigues MC, Haller E, Frisina-Deyo A, Mirtyl S et al (2012) Impaired blood-brain/spinal cord barrier in ALS patients. Brain Res 1469:114-128. https://doi.org/10.1016/j. brainres.2012.05.056

23. Ghassemifar MR, Sheth B, Papenbrock T, Leese HJ, Houghton FD, Fleming TP (2002) Occludin TM4(-): an isoform of the tight junction protein present in primates lacking the fourth transmembrane domain. J Cell Sci 115:3171-3180

24. Goncalves N, Simoes AT, Cunha RA, de Almeida LP (2013) Caffeine and adenosine a (2A) receptor inactivation decrease striatal neuropathology in a lentiviral-based model of Machado-Joseph disease. Ann Neurol 73:655-666. https://doi.org/10.1002/ana.23866

25. Halliday MR, Rege SV, Ma Q, Zhao Z, Miller CA, Winkler EA et al (2016) Accelerated pericyte degeneration and blood-brain barrier breakdown in apolipoprotein E4 carriers with Alzheimer's disease. J Cereb Blood Flow Metab 36:216-227. https://doi.org/10.1038/jcbfm.2015.44

26. Ikawa M, Kimura H, Kitazaki Y, Sugimoto K, Matsunaga A, Hayashi K et al (2018) Arterial spin labeling MR imaging for the clinical detection of cerebellar hypoperfusion in patients with spinocerebellar degeneration. J Neurol Sci 394:58-62. https://doi.org/10.1016/j.jns.2018.09.007

27. Kawaguchi Y, Okamoto T, Taniwaki M, Aizawa M, Inoue M, Katayama S et al (1994) CAG expansions in a novel gene for Machado-Joseph disease at chromosome 14q32.1. Nat Genet 8:221-228. https://doi.org/10.1038/ ng1194-221

28. Kazachkova N, Raposo M, Montiel R, Cymbron T, Bettencourt C, SilvaFernandes A et al (2013) Patterns of mitochondrial DNA damage in blood and brain tissues of a transgenic mouse model of Machado-Joseph disease. Neurodegener Dis 11:206-214. https://doi.org/10.1159/000339207

29. Kim ES, Lee SK, Kwon MJ, Lee PH, Ju YS, Yoon DY et al (2016) Assessment of blood-brain barrier permeability by dynamic contrastenhanced MRI in transient middle cerebral artery occlusion model after localized brain cooling in rats. Korean J Radiol 17:715-724. https://doi. org/10.3348/kj.2016.17.5.715

30. Kirk J, Plumb J, Mirakhur M, McQuaid S (2003) Tight junctional abnormality in multiple sclerosis white matter affects all calibres of vessel and is associated with blood-brain barrier leakage and active demyelination. J Pathol 201:319-327. https://doi.org/10.1002/path.1434

31. Kook SY, Hong HS, Moon M, Ha CM, Chang S, Mook-Jung I (2012) Abeta (1)(-)(4)(2)-RAGE interaction disrupts tight junctions of the blood-brain barrier via Ca (2)(+)-calcineurin signaling. J Neurosci 32:8845-8854. https:// doi.org/10.1523/JNEUROSCl.6102-11.2012

32. Li W, Long JA, Watts LT, Jiang Z, Shen Q, Li Y et al (2014) A quantitative MRI method for imaging blood-brain barrier leakage in experimental traumatic brain injury. PLoS One 9:e114173. https://doi. org/10.1371/journal.pone.0114173

33. Li Y, Fanning AS, Anderson JM, Lavie A (2005) Structure of the conserved cytoplasmic C-terminal domain of occludin: identification of the ZO-1 binding surface. J Mol Biol 352:151-164. https://doi.org/10. 1016/j.jmb.2005.07.017

34. Liebner S, Dijkhuizen RM, Reiss Y, Plate KH, Agalliu D, Constantin G (2018) Functional morphology of the blood-brain barrier in health and disease. Acta Neuropathol 135:311-336. https://doi.org/10.1007/s00401-018-1815-1

35. Lim RG, Quan C, Reyes-Ortiz AM, Lutz SE, Kedaigle AJ, Gipson TA et al (2017) Huntington's disease iPSC-derived brain microvascular endothelial cells reveal WNT-mediated Angiogenic and blood-brain barrier deficits. Cell Rep 19:1365-1377. https://doi.org/10.1016/j.celrep.2017.04.021

36. Liu J, Jin X, Liu KJ, Liu W (2012) Matrix metalloproteinase-2-mediated occludin degradation and caveolin-1-mediated claudin-5 redistribution contribute to blood-brain barrier damage in early ischemic stroke stage. J Neurosci 32:3044-3057. https://doi.org/10.1523/JNEUROSCl.6409-11.2012
37. Magaki S, Tang Z, Tung S, Williams CK, Lo D, Yong WH et al (2018) The effects of cerebral amyloid angiopathy on integrity of the blood-brain barrier. Neurobiol Aging 70:70-77. https://doi.org/10.1016/j.neurobiolaging. 2018.06.004

38. Marco S, Skaper SD (2006) Amyloid beta-peptide1-42 alters tight junction protein distribution and expression in brain microvessel endothelial cells. Neurosci Lett 401:219-224. https://doi.org/10.1016/j.neulet.2006.03.047

39. Maruyama H, Nakamura S, Matsuyama Z, Sakai T, Doyu M, Sobue G et al (1995) Molecular features of the CAG repeats and clinical manifestation of Machado-Joseph disease. Hum Mol Genet 4:807-812

40. Matos CA, de Almeida LP, Nobrega C (2019) Machado-Joseph disease/ spinocerebellar ataxia type 3: lessons from disease pathogenesis and clues into therapy. J Neurochem 148:8-28. https://doi.org/10.1111/jnc.14541

41. McCaffrey G, Staatz WD, Quigley CA, Nametz N, Seelbach MJ, Campos CR et al (2007) Tight junctions contain oligomeric protein assembly critical for maintaining blood-brain barrier integrity in vivo. J Neurochem 103:25402555. https://doi.org/10.1111/j.1471-4159.2007.04943.x

42. Mendonca LS, Nobrega C, Hirai H, Kaspar BK, Pereira de Almeida L (2015) Transplantation of cerebellar neural stem cells improves motor coordination and neuropathology in Machado-Joseph disease mice. Brain 138:320-335. https://doi.org/10.1093/brain/awu352

43. Montagne A, Barnes SR, Sweeney MD, Halliday MR, Sagare AP, Zhao Z et al (2015) Blood-brain barrier breakdown in the aging human hippocampus. Neuron 85:296-302. https://doi.org/10.1016/j.neuron.2014.12.032

44. Montagne A, Zhao Z, Zlokovic BV (2017) Alzheimer's disease: a matter of blood-brain barrier dysfunction? J Exp Med 214:3151-3169. https://doi.org/ 10.1084/jem.20171406

45. Nascimento-Ferreira I, Santos-Ferreira T, Sousa-Ferreira L, Auregan G, Onofre I, Alves $S$ et al (2011) Overexpression of the autophagic beclin-1 protein clears mutant ataxin-3 and alleviates Machado-Joseph disease. Brain 134: 1400-1415. https://doi.org/10.1093/brain/awr047

46. Nation DA, Sweeney MD, Montagne A, Sagare AP, D'Orazio LM, Pachicano $M$ et al (2019) Blood-brain barrier breakdown is an early biomarker of human cognitive dysfunction. Nat Med 25:270-276. https://doi.org/10.1038/ s41591-018-0297-y

47. Nobrega C, Mendonca L, Marcelo A, Lamaziere A, Tome S, Despres G et al (2019) Restoring brain cholesterol turnover improves autophagy and has therapeutic potential in mouse models of spinocerebellar ataxia. Acta Neuropathol. https://doi.org/10.1007/s00401-019-02019-7

48. Oliveira Miranda C, Marcelo A, Silva TP, Barata J, Vasconcelos-Ferreira A, Pereira D et al (2018) Repeated Mesenchymal stromal cell treatment sustainably alleviates Machado-Joseph disease. Mol Ther 26:2131-2151. https://doi.org/10.1016/j.ymthe.2018.07.007

49. Oliveira SR, Castelhano J, Sereno J, Vieira HLA, Duarte CB, Castelo-Branco M (2020) Response of the cerebral vasculature to systemic carbon monoxide administration - regional differences and sexual dimorphism. Eur J Neurosci. https://doi.org/10.1111/ejn.14725

50. Onofre I, Mendonca N, Lopes S, Nobre R, de Melo JB, Carreira IM et al (2016) Fibroblasts of Machado Joseph disease patients reveal autophagy impairment. Sci Rep 6:28220. https://doi.org/10.1038/srep28220

51. Paulson HL, Das SS, Crino PB, Perez MK, Patel SC, Gotsdiner D et al (1997) Machado-Joseph disease gene product is a cytoplasmic protein widely expressed in brain. Ann Neurol 41:453-462. https://doi.org/10.1002/ana. 410410408

52. Pietronigro E, Zenaro $\mathrm{E}$, Constantin $\mathrm{G}$ (2016) Imaging of leukocyte trafficking in Alzheimer's disease. Front Immunol 7:33. https://doi.org/10.3389/fimmu. 2016.00033

53. Pietronigro EC, Della Bianca V, Zenaro E, Constantin G (2017) NETosis in Alzheimer's disease. Front Immunol 8:211. https://doi.org/10.3389/fimmu. 2017.00211

54. Quagliarello VJ, Ma A, Stukenbrok H, Palade GE (1991) Ultrastructural localization of albumin transport across the cerebral microvasculature during experimental meningitis in the rat. J Exp Med 174:657-672. https:// doi.org/10.1084/jem.174.3.657

55. Rodrigues AJ, do Carmo Costa M, Silva TL, Ferreira D, Bajanca F, Logarinho E et al (2010) Absence of ataxin-3 leads to cytoskeletal disorganization and increased cell death. Biochim Biophys Acta 1803:1154-1163. https://doi.org/ 10.1016/.j.bamcr.2010.07.004

56. Rossner W, Tempel K (1966) Quantitative determination of the permeability of the so-called blood-brain barrier of Evans blue (T 1824). Med Pharmacol Exp Int J Exp Med 14:169-182 
57. Ryu JK, Davalos D, Akassoglou K (2009) Fibrinogen signal transduction in the nervous system. J Thromb Haemost 7(Suppl 1):151-154. https://doi.org/ 10.1111/j.1538-7836.2009.03438.x

58. Schubert-Unkmeir A, Konrad C, Slanina H, Czapek F, Hebling S, Frosch M (2010) Neisseria meningitidis induces brain microvascular endothelial cell detachment from the matrix and cleavage of occludin: a role for MMP-8. PLoS Pathog 6:e1000874. https://doi.org/10.1371/journal.ppat.1000874

59. Shi Y, Wang C, Huang F, Chen Z, Sun Z, Wang J et al (2015) High serum GFAP levels in SCA3/MJD may not correlate with disease progression. Cerebellum 14:677-681. https://doi.org/10.1007/s12311-015-0667-7

60. Simoes AT, Goncalves N, Koeppen A, Deglon N, Kugler S, Duarte CB et al (2012) Calpastatin-mediated inhibition of calpains in the mouse brain prevents mutant ataxin 3 proteolysis, nuclear localization and aggregation, relieving MachadoJoseph disease. Brain 135:2428-2439. https://doi.org/10.1093/brain/aws177

61. Soong BW, Liu RS (1998) Regional decrease in brain glucose metabolism in asymptomatic gene carriers of Machado-Joseph disease: a preliminary report. Zhonghua Yi Xue Za Zhi (Taipei) 61:121-126

62. Spampinato SF, Merlo S, Sano Y, Kanda T, Sortino MA (2017) Astrocytes contribute to Abeta-induced blood-brain barrier damage through activation of endothelial MMP9. J Neurochem 142:464-477. https://doi.org/10.1111/ jnc.14068

63. Takiyama Y, Nishizawa M, Tanaka H, Kawashima S, Sakamoto H, Karube Y et al (1993) The gene for Machado-Joseph disease maps to human chromosome 14q. Nat Genet 4:300-304. https://doi.org/10.1038/ng0793-300

64. Todi SV, Winborn BJ, Scaglione KM, Blount JR, Travis SM, Paulson HL (2009) Ubiquitination directly enhances activity of the deubiquitinating enzyme ataxin-3. EMBO J 28:372-382. https://doi.org/10.1038/emboj.2008.289

65. Torashima T, Koyama C, lizuka A, Mitsumura K, Takayama K, Yanagi S et al (2008) Lentivector-mediated rescue from cerebellar ataxia in a mouse model of spinocerebellar ataxia. EMBO Rep 9:393-399. https://doi.org/10. 1038/embor.2008.31

66. Villasenor R, Lampe J, Schwaninger M, Collin L (2019) Intracellular transport and regulation of transcytosis across the blood-brain barrier. Cell Mol Life Sci 76:1081-1092. https://doi.org/10.1007/s00018-018-2982-x

67. Vorbrodt AW, Dobrogowska DH (2004) Molecular anatomy of interendothelial junctions in human blood-brain barrier microvessels. Folia Histochem Cytobiol 42:67-75

68. Walker JB, Nesheim ME (1999) The molecular weights, mass distribution, chain composition, and structure of soluble fibrin degradation products released from a fibrin clot perfused with plasmin. J Biol Chem 274:52015212. https://doi.org/10.1074/jbc.274.8.5201

69. Wan W, Cao L, Liu L, Zhang C, Kalionis B, Tai X et al (2015) Abeta (1-42) oligomer-induced leakage in an in vitro blood-brain barrier model is associated with up-regulation of RAGE and metalloproteinases, and downregulation of tight junction scaffold proteins. J Neurochem 134:382-393. https://doi.org/10.1111/jnc.13122

70. Willott E, Balda MS, Heintzelman M, Jameson B, Anderson JM (1992) Localization and differential expression of two isoforms of the tight junction protein ZO-1. Am J Phys 262:C1119-C1124. https://doi.org/10.1152/ajpcell. 1992.262.5.C1119

71. Yang Z, Huang C, Wu Y, Chen B, Zhang W, Zhang J (2019) Autophagy protects the blood-brain barrier through regulating the dynamic of Claudin5 in short-term starvation. Front Physiol 10:2. https://doi.org/10.3389/fphys. 2019.00002

72. Yates RL, Esiri MM, Palace J, Jacobs B, Perera R, DeLuca GC (2017) Fibrin (ogen) and neurodegeneration in the progressive multiple sclerosis cortex. Ann Neurol 82:259-270. https://doi.org/10.1002/ana.24997

73. Yong WW (2005) Metalloproteinases: mediators of pathology and regeneration in the CNS. Nat Rev Neurosci 6:931-944. https://doi.org/10.1038/nrn1807

74. Zhu L, Li X, Zeng R, Gorodeski GI (2006) Changes in tight junctional resistance of the cervical epithelium are associated with modulation of content and phosphorylation of occludin 65-kilodalton and 50-kilodalton forms. Endocrinology 147:977-989. https://doi.org/10.1210/en.2005-0916

75. Zlokovic BV (2008) The blood-brain barrier in health and chronic neurodegenerative disorders. Neuron 57:178-201. https://doi.org/10.1016/j. neuron.2008.01.003

\section{Publisher's Note}

Springer Nature remains neutral with regard to jurisdictional claims in published maps and institutional affiliations.

\section{Ready to submit your research? Choose BMC and benefit from}

- fast, convenient online submission

- thorough peer review by experienced researchers in your field

- rapid publication on acceptance

- support for research data, including large and complex data types

- gold Open Access which fosters wider collaboration and increased citations

- maximum visibility for your research: over $100 \mathrm{M}$ website views per year

At BMC, research is always in progress.

Learn more biomedcentral.com/submissions 